\title{
Incentives versus Synergies in Markets for Talent*
}

\author{
Bharat N. Anand ${ }^{\dagger}$ \\ Harvard University
}

\author{
Alexander Galetovic ${ }^{\ddagger}$ \\ Universidad de Chile
}

January 2004

\author{
Alvaro Stein ${ }^{\S}$ \\ Universidad de Chile
}

\begin{abstract}
We study what type of organization will host projects where talented individuals are pivotal. A cash-constrained and talented individual must invest in acquiring a skill essential to execute a project. Skill acquisition may be financed by either a corporation, which inserts the project into its pre-existing organization; or a specialist that finances single-project firms. The specialist can make talent the residual claimant. The corporation can exploit cross-project synergies by centralizing operations, which weakens incentives. Property rights may be weak: talent may leave and develop the project elsewhere after acquiring the skill.

We find that weak property rights help corporations: for a given level of centralization, both effort and profits increase as property rights weaken. When the corporation can freely choose the strength of property rights and centralization, we find that, first, weak property rights are preferred; and, second, the corporation always chooses some centralization, eschewing first-best effort incentives. Moreover, whenever the corporation finances, it is socially efficient.

We apply the model to examine several apparently puzzling phenomena in markets for talent. These include dominance by large firms despite severe conflicts of interest and high effort exertion by talent within large firms.
\end{abstract}

Key words: conflicts of interest, corporations, outside option, second-best principle, self-dealing, weak property rights

JEL classification: D23, L23

\footnotetext{
* We are grateful to Felipe Balmaceda and Alejandro Jofré for helpful comments. Anand gratefully acknowledges financial support from the Division of Research at Harvard Business School. Galetovic gratefully acknowledges the financial support of Fondecyt, and the Hewlett Foundation under an institutional grant to CEA. Stein gratefully acknowledges the financial support of Fondecyt under a dissertation grant.

$\dagger$ Soldiers Field Road, Boston, MA 02163. Phone: (617) 495-5082; Fax: (617) 495-0355; email: banand@hbs.edu.

¥ Centro de Economia Aplicada (CEA), Departamento de Ingenieria Industrial, Av. Republica 701, Santiago, Chile. Phone: +56/2-678-4065; Fax: +56/2-689-7895; email: agaleto@dii.uchile.cl.

$\S$ Centro de Economia Aplicada (CEA), Departamento de Ingenieria Industrial, Av. Republica 701, Santiago, Chile. Phone: +56/2-678-4035; Fax: +56/2-689-7895; email: astein@dii.uchile.cl.
} 


\section{Introduction}

It is often claimed that talent requires strong incentives which are best provided by narrow-focused firms. Yet in most markets where talent is important, a surprisingly large amount of activity is done in corporations where incentive structures are blunt and organizations bureaucratic. For example, despite the success of venture capital over the past twenty years, around $90 \%$ of $\mathrm{R} \& \mathrm{D}$ is still done within corporations. In other industries like arts, sports, and entertainment, one sees similar patterns: talented individuals complain about the loss of creative freedom within corporations, yet recent trends are towards conglomeration rather than specialization by firms.

Besides blunt incentives, there are other reasons for talent to be suspicious of large firms. Corporations are notorious for self-dealing, conflicts of interest and expropriation. Recent lawsuits by artists and producers against large entertainment conglomerates are illustrative. In 1998, David Duchovny, star of the hit television show X-Files, sued entertainment conglomerate News Corporation and its Fox Television Network, "[...] accusing Fox of limiting the potential back-end gross of the show - and thereby his take through profit participation points - by cutting sweetheart deals with Fox-owned entities at below-market prices." A few months later, producer Steven Bochko also filed a lawsuit against News Corporation for selling the show NYPD Blue (in which Bochko had a profit sharing stake) to its own cable channel, FX, at below-market prices, and observed that " [...] this is just the 1999 version of what they used to call "creative bookkeeping." 1 Similar complaints are heard in other industries.

These observations raise positive and normative questions. Why are most projects where talent is pivotal hosted by multi-business corporations? Why do talented individuals repeatedly transact with large firms where interest conflicts are severe, despite there being viable alternatives in the marketplace? And, how should one reconcile the empirical facts with the widely held view that narrow-focused firms and specialist financiers that offer strong incentives are the best places to locate projects that rely on talent? Indeed, is there a massive misallocation of talented individuals in the economy? These issues inform the central question of this paper: what type of organization should one expect to host projects where talented individuals are pivotal?

In our model talent becomes embodied in individuals and property rights are weak - talent may leave after acquiring skills. ${ }^{2}$ Two different organizations compete to host projects: on the one hand, the project may be set up as a standalone firm financed by a specialist financier (for example, an angel, a bank, a venture capitalist or an investment fund). On the other hand, a

\footnotetext{
${ }^{1}$ See "Media Mergers Bottom Line So Far? Lawsuits," Los Angeles Times, September 17, 1999.

${ }^{2}$ We use the term "talent" to highlight the wide applicability of these two characteristics. Thus, although salient differences exist in the nature of creative talent across industries, the characteristics of interest here are likely common to many of these settings, including the financing of actors, musicians, performers, scientific researchers, and athletes. Related to these characteristics (viz., embodied talent and weak property rights) is the notion of "inalienable" human capital that has been studied by Hart and Moore(1994) in the context of entrepreneurial finance.
} 
multi-project firm - called a "corporation" - may insert the project in its existing organization. The key difference between these two types of organizations stems from their impact on effort incentives. The specialist can write a contract that makes talent the residual claimant over project surplus, thus providing first-best effort incentives. ${ }^{3}$ By contrast, corporations face a tradeoff: a corporation can exploit synergies by centralizing operations; but as centralization increases, it is increasingly harder to make talent the residual claimant and incentives are blunted. ${ }^{4}$ One can think of many reasons why centralization weakens incentives, but in this paper we assume that it facilitates expropriation of the surplus created by the project. This assumption makes economic sense because by now it is well known that corporations can engage in many practices that make accounting uninformative. ${ }^{5}$ The relevant point is that expropriation implies that it is difficult to make talent a residual claimant-hence weaker incentives.

The main result is as follows. As property rights weaken, talent's outside option becomes more attractive, thus forcing the corporation to pay more. Hence, weaker property rights strengthen effort incentives and relax the incentives-synergies trade off-allowing the corporation to take advantage of synergies without sacrificing too many incentives. This gives the corporation an edge over the specialist financier and enlarges the scope of projects that the corporation finances. More than that, we find that corporate profits increase as property rights weaken; and corporations never choose to mimic specialists and eschew first-best effort incentives since it is always optimal to sacrifice some incentives to realize synergies. Last, and corporate financing is socially efficient whenever observed. Of course, if property rights are very weak (we give a precise meaning to 'very weak' below), financing will not occur.

It might seem strange to claim that corporations benefit from weak property rights, which are typically thought to hurt investment incentives. But the common intuition stems from models where imperfect appropriability is the only distortion. In this model we add a second distortion: the corporation cannot make talent residual claimant because centralization facilitates expropriation of the surplus created by the project. Now it turns out that when these two distortions interact, weak property rights cancel the deleterious effects of account manipulation on effort-an example

\footnotetext{
${ }^{3}$ There is a large literature arguing that specialist financiers provide powerful effort incentives. For example, Gompers and Lerner (2001) note that in venture-capital backed companies, “[...] the sensitivity of the CEO's payfor-performance is almost sixty times higher than it is in large, mature public companies."

${ }^{4}$ The incentive-synergies tradeoff has been studied by various authors, and labeled variously. For example, Hart and Holmstrom (2002) examine the tradeoff between "coordination" of units and the "independence" of managers in each unit, and Mailath et al (2003) study the tradeoff between "integration" and "worker initiative." Other authors have examined different costs of enhancing synergies. A recent example is Dessein et al (2003) who study how organizing to increase synergies compromises the firms's ability to adapt to local information.

${ }^{5}$ Holmstrom (1989), for example, notes that a firm "[...] has control of many levers to make accounting measures less reliable." Relatedly, New York State's Attorney General, Eliot Spitzer - after recently initiating investigations against several major investments banks that were accused of compromising the objectivity of their research activities to enhance their underwriting business - noted that "synergies is just another word for conflicts of interest."
} 
of the well-known second-best principle that two distortions may cancel out instead of adding up. ${ }^{6}$

Our paper is related to several strands of literature. A recent paper that studies the market for talent is Terviö's (2003). He shows that when talent can leave (i.e., using our terminology, when property rights are weak) too many persons of mediocre ability remain active after entering the market and the discovery of talent is inefficiently low. Our paper, by contrast, asks how the given stock of talent is allocated among different types of organizations and whether that allocation is efficient. In addition, the organizational heterogeneity that results from synergies suggests a mechanism that possibly moderates the inefficiency detected by Terviö: talent locates in firms that can use the surpluses created by synergies to offer wages that can be competitive with outside options.

The study of how organizational structure adjusts to deal with weak property rights is a theme also present in Morrison and Wilhelm (2003). In their model unskilled agents are trained by a firm but may be tempted to sell their labour to the highest bidder after acquiring tacit human capital. They show that the specifics of the partnership organization (i.e. opaqueness about the ability of candidates, illiquid partnership stakes, and specialization in human capital intensive experience goods) can be explained as adjustments to overcome this weak property right problem. Also like us, they study how the strength of property rights impact competing organizations differently. Specifically, they argue that the strengthening of property rights over time is one reason why partnerships are being replaced by joint-stock companies in industries like consulting or investment banking.

Our second-best result is reminiscent of some recent explanations for why firms invest in "general training" that improves worker's outside options. In particular, Acemoglu and Pischke $(1998,1999)$ argue that firms are more willing to finance training in general skills when labor-market distortions impair the mobility of workers. These distortions include search costs, informational asymmetries, or efficiency wages, and are assumed to be an exogenous feature of the labor market in general. In contrast, our paper examines a distortion that is endogenous to a particular form of organization. Consequently, organizational heterogeneity, rather than market characteristics, solves the free-riding problem. Another strand of the literature focuses on the reverse problem: if something "binds" workers to firms, what prevents firms from expropriating workers? For example, a paper with a mechanism that works similarly to ours is Balmaceda's (2003). He shows that firms may be willing to finance training in general skills that improve workers' outside options in order to stimulate them to invest in firm-specific human capital which firms can expropriate - again, two distortions cancel out.

The second best result suggests that corporations can be expected to prefer weaker property

\footnotetext{
${ }^{6}$ See Lipsey and Lancaster (1956) and Bhagwati (1971). The second-best principle says that in the face of preexisting distortions, policies that in isolation decrease efficiency can in fact increase it.
} 
rights. This result is proved formally in section 4. This is consistent with recent theoretical arguments that weak property rights may be socially and privately beneficial. For example, Boldrin and Levine (2002 and 2003, chapter 2) show that falling copying costs, which imply weaker property rights over the original innovation, may increase the present value of introducing an innovation if demand for the final product is elastic.

Last, other salient aspects of markets for talent as studied here are also relevant in R\&D. In particular, in markets for talent ideas are typically embodied in individuals who need to be motivated with strong incentives. Our focus on such a setting thus extends the literature that studies how entrepreneurial ventures will be financed (e.g. Aghion and Tirole [1994], Gans and Stern [2000], Hellmann [2002]). Whereas these studies assume that property rights over assets can be perfectly established and arbitrarily allocated, we analyze the consequences of weak property rights on effort incentives. Our paper is thus also related to a second strand of the R\&D literature that studies the effect of weak property rights on R\&D finance (e.g. Anton and Yao [1994, 1995, 2002] and Anand and Galetovic [2000]). We go beyond these papers by analyzing how effort incentives are affected by weak property rights and internal organization.

Before proceeding we call attention to a caveat. We are aware that the term "synergies" is sometimes used loosely and imprecisely. In this paper we use the term "synergies" to denote complementarities that can be exploited only within the boundaries of a firm. Thus synergies could arise from common assets (e.g. a brand name, a database, or routines) or shared activities (e.g. centralized manufacturing, purchasing, or sales) but cannot be accessed through the market or via contracts, perhaps due to transactions costs or contract incompleteness. Having defined what we mean, we will use the term throughout the rest of the paper without further apology.

The rest of the paper is organized as follows. In section 2, we describe the setup of the model and the timeline of the game. Section 3 examines competition between specialists and corporations, and characterizes the organizational location of projects in equilibrium. In section 4 , the model is used to shed light on some apparently puzzling phenomena that appear to characterize markets where talent is pivotal to projects: why corporations appear to dominate markets for talent, why effort exertion by talent is high despite blunt incentives within corporations, and why conflicts of interest persist in markets for talent. Specific applications include the financing of entrepreneurial ventures by venture capitalists versus corporations, the financing of television shows by specialist financiers versus entertainment conglomerates, and the financing of talent discovery by agents. Section 5 concludes. 


\section{The model}

\subsection{Setup}

Agents There are two periods: investment and execution of the project; and three dates: date 0 before investment; date 1, in-between investment and execution; and date 2, after execution of the project. The output of the investment phase is a "skill" that is necessary to develop a marketable idea or perform an activity. There are two types of organizations, the corporation $(c)$ and the specialist financier $(f)$. But to invest and execute the project, the input of a cashconstrained talented individual (henceforth referred to simply as "talent") is essential. All agents are risk-neutral. (Table 2.1 summarizes the notation.)

There is one and only one individual who can obtain the skill at cost $I$, but a measure $m$ look like her. Thus there is asymmetric information: while each individual knows her ability at date 0 , financiers do not. While all uncertainty is revealed after investment, talent is not verifiable and cannot be contracted upon. Thus organizations cannot attract talent by signing a contract saying "I will pay you $\$ X$ upon being revealed that you are talented." But individuals neither obtain utility from being financed nor divert funds during the investment phase. Thus, talent will selfselect provided that the financier does not pay anything beyond $I$ at date 0 or 1 . Such additional payment would attract a lemon with probability one.

Table 2.1: Notation

\begin{tabular}{ll}
\hline$I$ & Cost of acquiring skill. \\
$e \geq 0$ & Talent's effort. \\
$S(e)$ & Project's surplus (net of investment cost). \\
$p \in[0,1]$ & Strength of property rights. \\
$v \in[0,1]$ & Decentralization level. \\
$G(v)$ & Synergies. \\
$F_{s}$ & Specialist's offer. \\
$F_{c}$ & Corporation's offer. \\
\hline
\end{tabular}

The project To obtain the skill, $I$ must be spent. The fate of the project also depends on the intensity of nonverifiable effort $e$ exerted by talent during the investment phase. Thus, the project's surplus gross of investment cost, which materializes on date 2 , is a function $S(e)$. We assume that $e \geq 0$ and units are chosen so that effort level $e$ costs the equivalent of $e$ dollars to talent. Furthermore, we assume that $S^{\prime}>0, S^{\prime \prime}<0$ and $S(0)=0$ and, for convenience, that $S^{\prime \prime \prime}<0$. Two additional assumptions are needed to ensure non-trivial results: (i) $\lim _{e \rightarrow 0} S^{\prime}(e)=\infty$; and (ii) $\lim _{e \rightarrow \infty} S^{\prime}(e)=0$. This ensures that effort will be positive but bounded. 
Now call $e^{*}$ first-best effort, that is $e^{*}=\arg \max \{S(e)-e\}$. Given the conditions just imposed on $S$, there exists a unique $e^{*}$. We further assume that $S\left(e^{*}\right)-e^{*}-I>0$ : net surpluses are positive.

Property rights Following the literature on incomplete contracts (going back to Grossman and Hart [1986]) we assume that neither the skill nor the project can be described at time 0. Moreover, the skill is embodied in talent, and property rights over it are imperfect. We parametrize the strength of property rights as follows. If talent leaves at date 1 the financing organization can block the project's execution with probability $p \leq 1$ and retain its surplus. Hence, with probability $1-p$ talent can successfully execute the project elsewhere and appropriate all the surplus $S(e)$. It follows that $p=0$ parametrizes inexistent property rights; at the other extreme, $p=1$ corresponds to perfect property rights. ${ }^{7}$

Synergies, decentralization and surplus verification We assume that surplus verification is straightforward with a specialist financier. Hence, talent and the specialist financier can agree to any arbitrary sharing rule. Without loss of generality, we may restrict attention to sharing rules such that the specialist keeps amount $\min \left\{S(e), F_{s}\right\}$, with $F_{s}$ independent of $S(e)$, and talent receives $\max \left\{0, S(e)-F_{s}\right\}$, thereby being made a residual claimant if $e$ is such that $S(e) \geq F_{s}{ }^{8}$

The corporation is a bit more complex and its interaction with talent is characterized by $v \in[0,1]$, which parametrizes how decentralized the project is run. When $v=1$ the project is fully decentralized and run exactly like a single-project firm; at the other extreme, when $v=0$ the project is fully embedded in the corporation's structure.

The benefit of centralization are synergies $G(v)$, which fall with decentralization $\left(G^{\prime}<0\right)$ and disappear when the corporation replicates the single-project firm with $v=1$ (that is, $G(1)=0$ ). We further assume that $G^{\prime \prime}<0$. On the other hand, the cost of centralization is that it weakens the corporation's ability to make talent the residual claimant. Even if the corporation claims to do so, centralization makes surplus verification difficult, reducing talent's effort incentives.

We model this as follows. Just like the specialist, the corporation would like to make talent the residual claimant by choosing a sharing rule such that it receives $\min \left\{S(e), F_{c}\right\}$, where $F_{c}$ is a fixed payment from talent, and talent keeps $\max \left\{0, S(e)-F_{c}\right\}$. Nevertheless, with probability $v$ the corporation can misrepresent surplus and report any $S^{r} \in[0, S(e)]$. In that case talent receives

\footnotetext{
${ }^{7}$ The strength of property rights $p$ is exogenous. That is, the fact that talent cannot be prevented from walking away does not merely reflect weak enforcement of non-competes. Indeed, in many cases, it may be simply difficult to specify what the employee has stolen from you. In that case, contractually limiting her work elsewhere may be tantamount to slavery.

${ }^{8}$ Allowing linear contracts of the form $F_{s}+\mu S(e)$, or even more general ones, will not alter the results because it is always optimal for the specialist to make talent residual claimant by choosing $\mu=0$.
} 
$\max \left\{0, S^{r}-F_{c}\right\}$ according to the contract and the corporation keeps

$$
\min \left\{S(e), F_{c}+\left[S(e)-S^{r}\right]\right\}
$$

Note that by reporting $S^{r}=F_{c}$ the corporation can eventually keep all surplus. Hence, the more centralized the project, the less verifiable is surplus ${ }^{9}$.

\subsection{Timeline}

We now describe the time-line of the game, also summarized in Figure 1.

1. At date 0 the specialist financier and the corporation simultaneously offer contracts to talent. The specialist's offer is completely summarized by $F_{s}$, and the corporation's offer by $F_{c}$.

2. Specialist finances project: if talent accepts the specialist's offer, then:

- During the investment phase the specialist pays the investment cost $I$ and talent chooses effort $e$.

- At date 1 either of the following happens:

1. Talent leaves. The specialist sues and with probability $p$ blocks project execution and retains surplus $S(e)$; with probability $1-p$ the specialist is unsuccessful, talent executes the project and cashes surplus $S(e)$ at date 2 .

2. Talent stays. The project is executed and surplus is shared according to contract at date 2 .

3. Corporation finances project: if talent accepts the corporation's offer, then:

- During the investment phase the corporation pays the investment cost $I$ and talent chooses effort $e$.

- At date 1 , effort $e$ is observed by the financier. With probability $v$ surplus is verifiable; with probability $1-v$ surplus is not verifiable.

- If surplus is verifiable, talent decides whether to stay:

1. Talent leaves. The corporation sues and with probability $p$ blocks project execution and retains surplus $S(e)$; with probability $1-p$ the corporation is unsuccessful, talent executes the project and obtains surplus $S(e)$ at date 2 .

\footnotetext{
${ }^{9}$ The important implication of this assumption is that centralization limits the ability of the corporation of making talent the residual claimant. Of course, account manipulation is one of many reasons why centralization makes it difficult to achieve this (see, for example, Alchian and Demsetz [1972])
} 
2. Talent stays. The project is executed and surplus is shared according to contract at date 2 .

- If surplus is not verifiable, the corporation commits to report surplus $S^{r}$ and talent decides whether to stay.

1. Talent leaves. The corporation sues and with probability $p$ blocks project execution; with probability $1-p$ the corporation is unsuccessful, talent executes the project and obtains surplus $S(e)$ at date 2 .

2. Talent stays, the project is executed and the corporation reports surplus $S^{r}$ at date 2 which is shared according to contract.

\section{The organizational location of talent}

\subsection{A roadmap}

In this section we study whether talent will be financed in equilibrium and, if so, by what type of organization. There are several different cases to consider and the discussion will be easier to

follow if we start with a summary of results. This we do with the help of Figure 2, which shows who will finance in equilibrium for each pair $(v, p) \in[0,1] \times[0,1]$. It can be seen that the $(v, p)$ space is divided in four regions:

- Region I: When the corporation is sufficiently centralized ( $v$ is close to 0 ) and property rights are strong enough ( $p$ is close to 1 and in any case not smaller than $p^{*}$ ), talent will be financed by the specialist and locate in a single-project firm. Essentially, when the corporation is centralized effort incentives are weak and when property rights are strong talent's outside option is of little value. Thus, talent prefers to be financed by the specialist, who can commit to make her the residual claimant.

- Region IIa: If $v$ is large enough or, for a given $v$, property rights are weak enough, the corporation can offer a better deal to talent and therefore beat the specialist. As we will see, in part this is so because synergies make total surplus larger with the corporation. But the reason that the scope for corporate financing increases as $p$ falls is that effort incentives in the corporation are stronger when property rights are weaker.

- Region IIb: If property rights are weaker than $p^{*}$ the specialist is no longer willing to finance because weak property rights make holdup too attractive and retaining talent too expensive. But the corporation is still willing to finance because it benefits from synergies. 
- Region III. If property rights are too weak, neither organization will be willing to finance: holdup at date 1 is too attractive and neither organization can pay it and cover the investment cost $I$.

In what follows (section 3 and Appendix A) we will rigorously derive Figure 2 and efficiency results associated with each region. It is useful, however, to begin by studying talent's optimal effort decision in each possible case.

\subsection{Some simple economics of effort}

Effort when the specialist finances in equilibrium (Region I) Consider a pair $(v, p)$ such that the specialist finances in equilibrium (exact conditions for this to be the case will be derived in section 3.3.1). Then it is optimal to make talent the residual claimant. Thus, in Region I she must be maximizing $S(e)-e-F_{s}$ and exerting first best effort $e^{*}$. Hence:

Proposition 3.1. There is no effort distortion when the specialist finances.

In what follows we denote talent's equilibrium payoff when financed by a specialist by $\pi^{*}=S^{*}-$ $e^{*}-F_{s}$, with $S^{*} \equiv S\left(e^{*}\right)$.

Effort when the corporation finances in equilibrium (Regions IIa and IIb) Next consider a pair $(v, p)$ such that the corporation finances in equilibrium. When surplus is verifiable, talent is a residual claimant. On the other hand, the corporation must choose its report $S^{r} \in[0, S(e)]$ when surplus is not verifiable. The following lemma shows that the corporation will report a surplus which is just enough to pay talent her outside option.

Lemma 3.2 (Surplus expropriation). If surplus is not verifiable, then the corporation reports $S^{r}=(1-p) S(e)+F_{c}$ and talent receives her outside option. Surplus expropriation falls as property rights weaken.

Proof. If talent leaves, she receives her outside option $(1-p) S(e)$. If talent stays and the corporation reports $S^{r}=(1-p) S(e)+F_{c}$, she receives $S^{r}-F_{c}=(1-p) S(e)$. Thus, reporting something higher than $(1-p) S(e)+F_{c}$ would just leave money in talent's pocket, and reporting less would prompt talent to leave.

Thus if surplus is not verifiable talent receives exactly her outside option. The central implication of Lemma 3.2 is that the corporation will always extract some fraction of the surplus from talent, even if it claims to make her residual claimant. This result also suggests that talent's effort will increase 
as the value of her outside option increases. To obtain talent's effort, note that in equilibrium the corporation receives $F_{c}$ with probability $v$ and $S(e)-S^{r}+F_{c}=p S(e)$ with probability $1-v$ or

$$
T\left(F_{c} ; v, p\right) \equiv v F_{c}+(1-v) p S(e)
$$

in expected value. Function $T$ (for 'Transfer') highlights the fact that the corporation will keep some fraction of the surplus $S(e)$. In the rest of the paper we will omit the dependence of $T(\cdot)$ on $F_{c}$ whenever evaluated at $F_{c}=0$, which is the best contract the corporation can offer to talent.

Talent, on the other hand, must receive the rest of the project's surplus, viz

$$
S(e)-e-T\left(F_{c} ; v, p\right)
$$

Thus, when deciding how much effort to exert, talent maximizes (3.1). Optimal effort, denoted $e^{c}$, then satisfies the first order condition $S^{\prime}\left(e^{c}\right)=\frac{1}{1-(1-v) p} .{ }^{10}$ Of course, since $S^{\prime}\left(e^{c}\right)>1=S^{\prime}\left(e^{*}\right)$ $e^{c}<e^{*}$. That is, unless the corporation fully decentralizes the project, effort will be less than with the specialist financier.

How distorting is centralization? Since

$$
\frac{\partial e^{c}}{\partial v}=-\frac{p}{[1-(1-v) p]^{2} S^{\prime \prime}}>0
$$

it is clear that effort will be greater the more decentralized is the corporation. Since synergies fall with decentralization, we have the well-known tradeoff between incentives and synergies. But note also that

$$
\frac{\partial e^{c}}{\partial p}=\frac{1-v}{[1-(1-v) p]^{2} S^{\prime \prime}}<0
$$

This says that as long as the corporation is willing to finance, effort increases as property rights weaken. The mechanics is that weaker property rights increase the value of the outside option and moderate the corporation's inability to make talent a residual claimant. It is useful to state this explicitly:

Proposition 3.3. Weaker property rights substitute for a financier's commitment to make talent the residual claimant.

This second-best result - namely, one distortion (weaker property rights) moderates another (the inability of the corporation to report surplus truthfully) - is central to the analysis that follows in

\footnotetext{
${ }^{10}$ This expression is not defined for the pair $(v, p)=(0,1)$. Nevertheless, $S^{\prime}\left(e^{c}\right) \rightarrow \infty$ when $(v, p) \rightarrow(0,1)$ which implies that $e^{c}(0,1)=0$.
} 
the next section.

For convenience, in what follows we denote talent's payoff if financed by a specialist by

$$
\pi^{c}=S^{c}-e^{c}-T\left(F_{c} ; v, p\right)
$$

with $S^{c} \equiv S\left(e^{c}\right)$

Time consistent holdup Before proceeding we note two technical points. First, we obtained $e^{*}$ and $e^{c}$ assuming that talent chooses to stay at date 1 . But, one might wonder whether the decision to stay after exerting effort $e^{*}$ and $e^{c}$ is optimal at date 1 - that is, whether the optimization during the investment phase is time consistent.

Second, we ignored the possibility that talent may also accept an organization's offer and then choose effort knowing that she will leave at date 1 . In that case, talent would maximize choosing $e^{a}=\arg \max \{(1-p) S(e)-e\} .^{11}$

The following lemma shows that if the contract offered by the organization in equilibrium beats $(1-p) S\left(e^{a}\right)-e^{a}$, then the decision to stay is time consistent, i.e. it cannot happen that talent prefers to leave given that she has exerted effort with the intention to stay. Conversely, if talent maximizes $(1-p) S(e)-e$ with the intention to leave, then leaving is time consistent. For convenience, in what follows we denote talent's equilibrium payoff when she leaves by

$$
\pi^{a}=(1-p) S^{a}-e^{a}
$$

with $S^{a} \equiv S\left(e^{a}\right)$

Lemma 3.4 (Time consistent holdup). Suppose the specialist offers contract $F_{s}$ and the corporation contract $F_{c}$. Then:

(i) If $\max \left\{\pi^{a}, \pi^{*}, \pi^{c}\right\}=\pi^{a}$ talent accepts either offer and leaves at date 1 .

(ii) If $\max \left\{\pi^{a}, \pi^{*}, \pi^{c}\right\}=\pi^{c}$ talent accepts the corporation's offer and stays to execute the project

(iii) If $\max \left\{\pi^{a}, \pi^{*}, \pi^{c}\right\}=\pi^{*}$ talent accepts the specialist's offer and stays to execute the project.

Proof. See Appendix B.

Lemma 3.4 shows an important implication of time consistency:

\footnotetext{
${ }^{11}$ To see that this may be optimal, assume that the specialist offers a contract such that $F_{s}=S^{*}$ which talent takes. Then talent's payoff if she chooses $e=e^{*}$ and then stays is $S^{*}-S^{*}-e^{*}$, obviously less than $(1-p) S^{*}-e^{*}$, which in turn is less than $(1-p) S\left(e^{a}\right)-e^{a}$.
} 
Lemma 3.5. When either the specialist or the corporation finance in equilibrium, talent's payoff must be at least $\pi^{a}=(1-p) S^{a}-e^{a}$ in expected value.

It follows that to finance the project the organization will have to spend at least

$$
\mathcal{C}(p ; I) \equiv I+\pi^{a}=I+(1-p) S^{a}-e^{a} .
$$

In what follows we will call $\mathcal{C}$ the cost of financing the project. Note that it depends on the strength of property rights but not on $v$ : decentralization does not affect the value of talent's outside option. For this reason, the cost of the project is the same for both financiers.

Now a straightforward application of the envelope theorem implies that

$$
\frac{\partial \mathcal{C}(p ; I)}{\partial p}=\frac{\partial \pi^{a}}{\partial p}=-S^{a} \leq 0
$$

with equality only for $p=1$. In other words, weaker property rights increase the cost of financing the project.

\subsection{Incentives, synergies and the market for talent}

We can now characterize Figure 2. Roughly speaking, in regions I and IIa organizations compete: in the interior of region I the specialist can improve on any profitable offer the corporation can make to talent and the opposite happens in region IIa, where the corporation can offer a better deal. In region III, by contrast, organizations cannot recoup their investment, and none is willing to finance. Thus, a useful starting point to analyze whether talent will be financed and, if so, by whom, is to determine how much surplus is available to pay the project's cost and the transfer to talent under each type of organization.

\subsubsection{When will either organization finance?}

The two conditions here are derived from the trivial observation that an organization cannot transfer more than the surplus that the project creates. Gross of the investment cost $I$, the project creates surplus $S^{*}-e^{*}$ if financed by the specialist and $S^{c}-e^{c}+G(v)$ if financed by the corporation. Because the financier must receive at least $I$, talent $\pi^{a}$, and $\mathcal{C}(p ; I) \equiv I+\pi^{a}$, it follows that if the specialist finances in equilibrium, then

$$
\mathrm{RS}^{*}(p ; I) \equiv S^{*}-e^{*}-\mathcal{C}(p ; I) \geq 0 .
$$


This residual surplus is split when choosing $F_{s}$. Similarly, if the corporation finances in equilibrium,

$$
\operatorname{RS}^{c}(v, p ; I) \equiv S^{c}(v, p)-e^{c}(v, p)+G(v)-\mathcal{C}(p ; I) \geq 0,
$$

where we have made explicit the dependence of $e^{c}$ on $v$ and $p$. This residual surplus is split when $F_{c}$ is chosen (see Figure 3 ).

Conditions (3.2) and (3.3) are necessary for the respective organization to be willing to participate, otherwise the project does not generate enough surplus to pay its $\operatorname{cost} \mathcal{C}(p ; I)$ - either talent would leave or the organization would not recover $I$. Since the cost of financing the project $\mathcal{C}(p ; I)$ increases monotonically as $p$ falls and $\mathcal{C}(0 ; I)=S^{*}-e^{*}+I$, so that $\operatorname{RS}^{*}(0 ; I)=-I<0$, it follows that:

Lemma 3.6 (Strong versus weak property rights). There exists $p^{*}$ such that $S^{*}-e^{*}-\mathcal{C}\left(p^{*} ; I\right)=$ 0 . Moreover, $S^{*}-e^{*}-\mathcal{C}(p ; I) \geq 0$ if and only if $p \geq p^{*}$.

Henceforth we will say that property rights are "strong" if $p \geq p^{*}$, and "weak" otherwise. Thus, by definition the specialist finances only if property rights are strong.

Because $S^{c}-e^{c}$ increases as $p$ falls (property rights weaken), things are slightly more complicated with the corporation. But if $p$ is close enough to 0 , the cost effect dominates and, for each $v$, the corporation will not finance. To see this, note that, as shown in the appendix, $\mathrm{RS}^{c}$ is strictly concave in $p$. Thus, for each $v, \mathrm{RS}^{c}$ is either monotonically increasing or single-peaked in $[0,1]$. But, when $p=0, \operatorname{RS}^{c}(v, 0 ; I)=G(v)-I<0$, since $S^{a}-e^{a}=S^{c}-e^{c}=S^{*}-e^{*}$; and $\partial \operatorname{RS}^{c}(v, 0 ; I) / \partial p=S^{*}>0$. It follows that for each $v$ there exists some $\widetilde{p}(v)$ such that $\operatorname{RS}^{c}[v, \widetilde{p}(v) ; I]=0$ and $\operatorname{RS}^{c}(v, p ; I)<0$ for all $p<\widetilde{p}(v)$. Hence:

Lemma 3.7. For each $v$, the corporation is not willing to finance if $p$ is close enough to 0 .

Lemmas 3.6 and 3.7 show that region III is nonempty. Essentially, when property rights are weak and $p$ is close enough to 0 the project becomes too expensive because talent's outside option is too attractive.

In Appendix A.1 we fully characterize function $\widetilde{p}(v)$ using the implicit function theorem and some border values. To end this subsection, we show that when synergies are not too small, by which we mean $G(0)>I-p^{*} S^{a}$, then the corporation is willing to finance some projects when property rights are weak. That is, for all $v$ in $[0,1), \widetilde{p}(v)<p^{*}$, and region IIb is as in Figure $2 .{ }^{12}$

We will show this with an argument that will be repeatedly used in the rest of the paper, and is illustrated in Figure 4. Because $\operatorname{RS}^{c}(v, p ; I)$ is strictly concave in $p$ for all $v$ in $[0,1]$, it is

\footnotetext{
${ }^{12}$ When $G(0) \leq I-p^{*} S^{a}$, the scope for corporate financing is smaller, but still there will be an area with weak property rights where the corporation will finance. This case is examined in section 3.5 and Appendix $\mathrm{C}$ below.
} 
sufficient to show that $\operatorname{RS}^{c}\left(v, p^{*} ; I\right)>0$ for all $v$ in $[0,1)$. Then, $\operatorname{RS}^{c}(v, p ; I)>0$ for all $p$ in the interval $\left(\widetilde{p}(v), p^{*}\right)$; and, no matter how small, the interval exists. ${ }^{13}$

Note that because $e^{c}=e^{a}$ when $v=0$, it follows that $\pi^{c}=\pi^{a}=(1-p) S^{a}-e^{a}$ and $R S^{c}\left(0, p^{*} ; I\right)=G(0)-\left(I-p^{*} S^{a}\right)>0$. Moreover, $R S^{c}\left(1, p^{*} ; I\right)=R S^{*}\left(p^{*} ; I\right)=0$. These signs are sufficient to conclude that $R S^{c}\left(v, p^{*} ; I\right)>0$ for all $p$ in the interval $[0,1)$ and that it must reach a maximum in the interior of that interval.

\subsubsection{Competition between financiers}

We now study competition between the specialist and the corporation (regions I and IIa).

Perfect property rights $(p=1)$ It is useful to begin with the benchmark case of perfect property rights, that is $p=1$. As can be seen in Figure 2, the corporation will finance if $v$ is close enough to 1 , but the specialist will prevail when $v$ is small enough. Why?

To begin, note that talent obtains nothing if she leaves when $p=1$, thus $\pi^{a}=0$ and $\mathcal{C}(0 ; I)=I$. Then, as is proven in the appendix, it is sufficient for the specialist to finance if

$$
S^{*}-e^{*}-I>S^{c}(v, 1)-e^{c}(v, 1)+G(v)-I .
$$

which, rewriting, yields

$$
\left(S^{*}-e^{*}\right)-\left[S^{c}(v, 1)-e^{c}(v, 1)\right]>G(v) .
$$

Intuitively, synergies are not large enough to pay for the reduction in effort due to centralization. Hence the project creates a larger residual surplus if financed by the specialist, which can thus match any profitable offer that the corporation can make.

On the other hand, if

$$
S^{*}-e^{*}-I<S^{c}(v, 1)-e^{c}(v, 1)+G(v)-I
$$

holds, then the corporation will finance. Rewriting (3.6) gives:

$$
\left(S^{*}-e^{*}\right)-\left[S^{c}(v, 1)-e^{c}(v, 1)\right]<G(v) .
$$

That is, synergies are large enough to compensate the disincentive to effort caused by centralization.

Which condition holds depends on $v$, so one can study how residual surplus $\mathrm{RS}^{c}$ varies with it. Again the analysis is greatly simplified by the observation that $\mathrm{RS}^{c}$ is strictly concave in $v$. This

\footnotetext{
${ }^{13}$ This argument simply uses the fact that by continuity and concavity, we can deduce the existence and location of "zeros" (i.e. points where either the function's value or its derivative is zero) by analyzing the sign on two extremes and sometimes using additional information about the sign of the derivative at one of those extremes.
} 
implies that $\operatorname{RS}^{c}(v, 1, I)$ is either monotonic or single-peaked in $[0,1]$, and a simple examination of the function and the sign of its partial derivatives at the extremes suffices to fully characterize it.

At one extreme, if the corporation is fully centralized and $v=0$ talent would exert no effort. The reason is that the corporation would manipulate surplus with probability 1 and, in addition, talent's outside option is worth nothing because $p=1$. Thus $\operatorname{RS}^{c}(0,1 ; I)=G(0)-I<0$ by assumption, and it is clear that the specialist will finance (see Figure 2). At the same time, note that

$$
\frac{\partial \mathrm{RS}^{c}(v, 1 ; I)}{\partial v}=\left[S^{\prime}\left(e^{c}\right)-1\right] \times \frac{-1}{v^{2} S^{\prime \prime}\left(e^{c}\right)}+G^{\prime}(v),
$$

so that $\lim _{v \rightarrow 0} \partial \operatorname{RS}^{c}(v, 1 ; I) / \partial v=\infty .{ }^{14}$

At the other extreme, if $v=1$, the corporation and the specialist are identical and $\operatorname{RS}^{c}(1,1 ; I)>$ 0 . But $\partial \operatorname{RS}^{c}(1,1 ; I) / \partial v=G^{\prime}(1)<0$ : because $e^{c}=e^{*}$ when $v=1$, the effect on effort of slightly reducing $v$ is second-order small, and only the first-order effect on synergies matters. Hence, the corporation will finance if $v$ is close enough to 1 . Thus, the following results follow from the concavity of $\mathrm{RS}^{c}$ :

Proposition 3.8 (Perfect property rights). (a) There exists $v_{h}<1$ such that $\operatorname{RS}^{c}\left(v_{h}, 1 ; I\right)=$ $\mathrm{RS}^{*}(1 ; I)$.

(b) The corporation finances for all $v \in\left(v_{h}, 1\right)$; the specialist finances for all $v \in\left[0, v_{h}\right)$.

(c) There exists $v^{*} \in\left(v_{h}, 1\right)$ such that $\operatorname{RS}^{c}(v, 1 ; I)$ is maximal.

The economics of Proposition 3.8 reflects the central trade off between synergies and effort incentives. When the corporation is sufficiently decentralized it can take advantage of synergies without affecting incentives too much - decentralization makes credible its claim to make talent the residual claimant. But as the corporation becomes centralized, the incentive cost becomes increasingly important, and at some point dominates the benefits from synergies. From then on, the specialist can offer a better deal to talent.

Interestingly, part (c) indicates that if the corporation could freely choose its level of decentralization, it would optimally sacrifice incentives $\left(v^{*}<1\right)$ and yet offer talent a better deal than the specialist. This is just the consequence of the trade-off being weak when $v$ is large enough so that the gain in synergies outweighs the loss of effort incentives, and foreshadows a more general result in section 3.4 .

Competition with $p<1$ Because $\mathrm{RS}^{c}$ is concave in $v$ for all $p$, competition works similarly whenever $p<1$. Nevertheless, as can be deduced from Figure 2, weaker property rights enlarge the scope of corporate financing. Why? Consider $v$ such that

\footnotetext{
${ }^{14}$ When $v=0, e^{c}=0$. Moreover, $\lim _{e \rightarrow 0} S^{\prime}(e)=\infty$.
} 


$$
S^{*}-e^{*}-\mathcal{C}(p ; I)=S^{c}(v, p)-e^{c}(v, p)+G(v)-\mathcal{C}(p ; I),
$$

and then slightly decrease $p$ to $p^{\prime}=p-d p$. Clearly, the cost of financing the project, $\mathcal{C}(p ; I)$, increases for both organizations at the same rate. But we know from Proposition 3.3 that $\partial e^{c} / \partial p<0-$ when property rights are weaker talent exerts more effort because her outside option is more valuable. Because effort increases as $p$ falls, $S^{c}-e^{c}$ also increases as $p$ falls, thereby partly (but not completely) compensating for the increase in costs and

$$
S^{*}-e^{*}-\mathcal{C}\left(p^{\prime} ; I\right)<S^{c}\left(v, p^{\prime}\right)-e^{c}\left(v, p^{\prime}\right)+G(v)-\mathcal{C}\left(p^{\prime} ; I\right) .
$$

It follows that one can distinguish two effects of weaker property rights: (i) first, projects become more expensive, regardless of who finances; (ii) second, projects financed by the corporation become relatively less expensive.

This yields the following central result:

Result 3.1 (Property rights and the incentive-synergies tradeoff). Weak property rights reduce the incentive cost of synergies and enlarge the scope of corporate financing.

Result 3.1 has the additional implication that weaker property rights make the corporation strictly better off whenever it competes with the specialist. To see why, assume that the corporation finances. Because of competition, talent must receive at least her outside option plus all the residual surplus she could receive if financed by the specialist, viz. $\pi^{a}+\mathrm{RS}^{*}(p, I)$-otherwise talent would choose the specialist. Hence, competition increases the cost for the corporation of executing the project by $\operatorname{RS}^{*}(p, I)$ and it will finance only if

$$
S^{c}-e^{c}+G(v)-\mathcal{C}(p ; I)-\operatorname{RS}^{*}(p, I)=S^{c}-e^{c}+G(v)-\left(S^{*}-e^{*}\right) \geq 0
$$

It is clear that this expression increases as $p$ falls because weaker property rights strengthen incentives and increase $S^{c}-e^{c}$. Hence, the part of residual surplus that can be appropriated by the corporation increases: ${ }^{15}$

Proposition 3.9. As long as there is competition, the corporation's profit increases as property rights weaken.

Proposition 3.9 may seem surprising in view of the widespread belief that weaker property rights hurt financiers. What is the logic behind it? The first part is that competition effectively

\footnotetext{
${ }^{15}$ As mentioned before, we do not model the bargaining game between talent and the financier, but in any case our claim is valid as long as the corporation's payoff is increasing in $S^{c}-e^{c}+G(v)-\left(S^{*}-e^{*}\right)$.
} 
makes the cost of financing the project independent of $p$ because talent's outside option is no longer restrictive. With strong property rights, the cost for the corporation of attracting talent changes to the surplus that talent would obtain in a stand-alone project financed by the specialist. The second part we have already discussed: the outside option is more valuable when property rights are weaker, so incentives to exert effort increase.

Competition and efficiency Return to the case of perfect property rights $(p=1)$. Conditions (3.5) and (3.7) suggest that the outcome of competition is influenced by the following efficiency comparison: roughly speaking, the corporation finances when synergies compensate for lost incentives, and the converse occurs when they don't. In what follows, we show that financing by the specialist may occur even when the corporation is more efficient, but the opposite case cannot occur-that is, we will now show that

$$
S^{*}-e^{*}>\left[S^{c}(v, p)-e^{c}(v, p)\right]+G(v)
$$

is sufficient for the specialist to finance, whereas the converse,

$$
S^{c}(v, p)-e^{c}(v, p)+G(v) \geq S^{*}-e^{*}
$$

is only necessary for the corporation to finance.

To see why (3.8) is sufficient, note that by choosing $F_{s}=I$ the specialist can transfer all residual surplus $\operatorname{RS}^{*}(p, I)$ to talent. Hence, whenever (3.8) holds, the specialist can beat the best offer that the corporation could possibly make.

Like the specialist, the corporation would like to set $T\left(F_{c} ; v, p\right)$ close to $I$ whenever $(3.9)$ holds and competition is strong enough. Nevertheless, because $T\left(F_{c} ; v, p\right)=v F_{c}+(1-v) p S^{c}$ and $F_{c} \geq 0$, the corporation is constrained by non-verifiability to keep no less than $(1-v) p S^{c}$ in expected value. Hence, if the corporation is sufficiently centralized or property rights are strong enough, talent cannot receive all residual surplus $\operatorname{RS}^{c}(v, 1 ; I)$ because $(1-v) p S^{c}>I$. For this reason, it may happen that despite of significant synergies, the corporation may not be able to transfer enough surplus to talent despite being more efficient.

To formally study this transfer problem and its consequences, note that

$$
\pi^{c}(0 ; v, p)=S^{c}-e^{c}-T(0 ; v, p) \geq S^{*}-e^{*}-I=\pi^{*}(I)
$$

must hold in addition to (3.9) for the corporation to finance. In Appendix A.2 it is shown that 
there exists a convex and increasing function $t:[0,1] \rightarrow\left[p^{*}, 1\right]$ such that

$$
\pi^{c}[0 ; v, t(v)]=\pi^{*}(I)
$$

for $v \leq v_{t}$ (see Figure 5). For each $v, t(v)$ is the largest possible $p$ such that the corporation can transfer enough to beat the best possible offer of the specialist. Essentially, when $v<v_{t}$ property rights are too strong beyond some point $t(v)$, so that talent's outside option is not worth enough.

At the same time, in Appendix A.2 we show that there exists a strictly concave and increasing function $h:[0,1] \rightarrow\left[p^{*}, 1\right]$ such that

$$
S^{c}[v, h(v)]-e^{c}[v, h(v)]+G(v)-\left(S^{*}-e^{*}\right)=0
$$

for all $v \leq v_{h}$ (see Figure 5). For each $v$, this function indicates the maximum $p$ such that the corporation is more efficient than the specialist - as we have already seen, stronger property rights weaken incentives in the corporation because the outside option is worth less.

Now the following lemma is proven in Appendix A.2:

Lemma 3.10. If $G(0)>I-p^{*} S^{a}$, then $t(0)>p^{*}$ and region Ib in Figure 5 is nonempty.

That is, if synergies are large enough, inefficient financing cannot be ruled out. This yields the following result:

Result 3.2 (Efficiency of corporate financing). Corporate financing is efficient when observed, but specialist financing may not be.

Result 3.2 is just a consequence of assuming that corporate financing is affected by a distortion, whereas specialist financing is not. The distortion stems from the limited ability of the corporation to make talent residual claimant. Specifically, the corporation cannot directly transfer the synergy to talent (technically, this implies that function $t$ is independent of the synergy $G$ ), which creates the inefficiency.

The efficiency of corporate financing might seem surprising since corporations, not specialists, are often associated with inefficient outcomes. But the point is that Result 3.2 should be expected to obtain in any equilibrium analysis. That is, if one believed that specialist financiers offered first best incentives to talent, then it follows that whenever corporate financing is observed, it must be more efficient. Conversely, for observed corporate financing to be inefficient, as is often claimed, it must be because of some (typically unmodeled) distortion specific to specialist financing.

In practice, Result 3.2 suggests that one should have a strong presumption that corporate financing is efficient whenever observed, precisely because corporations are subject to more distortions than specialists.. 


\subsection{Endogenous organizational forms}

\subsubsection{Endogenizing decentralization and the strength of property rights}

So far we have assumed that $v$ and $p$ are exogenous. In many settings, this makes sense: corporations do not routinely adjust their existing internal organizational structure to accomodate the marginal project, and the strength of property rights often depends on factors beyond the control of a single firm. That said, one should also expect organizations to adapt. In what follows we examine the cases when corporations could freely choose the level of centralization and the strength of property rights. The central results are that the corporation would never choose to mimic the specialist, and would choose property rights to be weak.

Endogenous decentralization Suppose the corporation can choose the level of decentralization $v$ for a given $p$. We already know that it will not mimic the specialist when property rights are weak because it could not pay talent's outside option. By centralizing the project the corporation takes advantage of synergies which can then be used to pay for talent's outside option. Beyond a certain amount of centralization however, the gains from synergies are outweighted by the incentive cost of centralization, and residual surplus $\mathrm{RS}^{c}$ falls. A similar argument holds when property rights are strong. The only difference is that talent's outside option is now the specialist's offer, which does not change with centralization.

Formally, if the corporation could choose decentralization $v$, it would maximize $\Delta(v, p, I)$ where

$$
\Delta(v, p, I)= \begin{cases}\operatorname{RS}^{c}(v, p, I) & \text { if } \quad p \leq p^{*} \\ \operatorname{RS}^{c}(v, p, I)-\operatorname{RS}^{*}(p, I) & \text { if } \quad p>p^{*}\end{cases}
$$

Function $\Delta(v, p, I)$, defined for convenience to unify the weak and strong property rights cases, is the same as in section 3.3 when property rights are strong, and is equal to the corporation's residual surplus when property rights are weak. By defining $\Delta(v, p, I)$ in this way, and ignoring the transfer problem, we know that the corporation will finance if and only if $\Delta(v, p, I) \geq 0$. The following lemma implicitly characterizes optimal decentralization as a function of the strength of property rights.

Lemma 3.11. Optimal decentralization can be represented by a continuous and strictly increasing function $g_{v}:[0,1] \rightarrow[0,1]$ in $p$ with $g_{v}(1)=v^{*}<1$.

Proof. Fix $p=1$. Then between the $\max \left\{v_{h}, v_{t}\right\}$ and 1 , the corporation's utility function is positive (and concave) and thus the optimal centralization level $g_{v}(1)=v^{*}$ lies between those values. Both with weak and strong property rights, the first order condition is the same and is 
given by

$$
\frac{\partial \Delta}{\partial v}=\frac{\partial e^{c}}{\partial v}\left[S^{\prime}\left(e^{c}\right)-1\right]+G^{\prime}(v)=0 .
$$

Thus, $g_{v}(p)$ is implicitly defined by

$$
\frac{\partial \Delta}{\partial v}\left[g_{v}(p), p\right]=0
$$

Totally differentiating we have

$$
\left\{\left[S^{\prime}\left(e^{c}\right)-1\right] \frac{\partial^{2} e^{c}}{\partial v^{2}}+\left(\frac{\partial e^{c}}{\partial v}\right)^{2} S^{\prime \prime}+G^{\prime \prime}\right\} d g_{v}+\left\{\left[S^{\prime}\left(e^{c}\right)-1\right] \frac{\partial^{2} e^{c}}{\partial v \partial p}+\frac{\partial e^{c}}{\partial v} \frac{\partial e^{c}}{\partial p} S^{\prime \prime}\right\} d p=0
$$

and using the signs calculated in Appendix A we know that the first expression in brackets is strictly negative and the second is strictly positive. It follows that $\frac{d g_{v}}{d p}>0$.

Figure 6 characterizes the inverse of the $g_{v}$ function with the properties described above; that is, $g_{v}$ is the function that, for any given $v$, characterizes the $p$ that yields that particular $v$ to be optimal. ${ }^{16}$

With endogenous $v$, it should not be surprising that the corporation can beat out the specialist when competing for talent (Figure 6). What is surprising, however, is that in doing so, it never mimics the specialist (choosing $v=1$ ):

Result 3.3 (Endogenous decentralization). Optimal decentralization increases with stronger property rights, but never reaches full decentralization.

To see why the corporation would never choose to mimic the specialist, note that the first order condition is

$$
\frac{\partial \Delta}{\partial v}=\frac{\partial e^{c}}{\partial v}\left[S^{\prime}\left(e^{c}\right)-1\right]+G^{\prime}(v)=0
$$

At $v=1 G^{\prime}(1)<0$ and $S^{c}-e^{c}=S^{*}-e^{*}$. Hence, by slightly increasing centralization the corporation gains a first order increase in synergies, while the fall in surplus due to weakened incentives is second-order small.

Similarly, as $p$ falls the corporation's ability to make talent residual claimant increases and the difference $S^{\prime}\left(e^{c}\right)-1$ falls. Being less costly, the corporation would optimally decide to centralize more.

Endogenous property rights Now consider the problem faced by a corporation that can somehow choose the strength of property rights. Does the corporation prefer strong property rights? We already know (Proposition 3.9) as long as there is competition between financiers, the corporation

\footnotetext{
${ }^{16}$ Note that the inverse is defined only for $v \leq v^{*}$ because $v>v^{*}$ will never be an optimum. See Proposition 3.8 .
} 
is made better off by weaker property rights. Thus, if we restrict to areas I and IIa of Figure 2, the corporation would like to choose $p^{*}$. This section proves a stronger result. That is, as long as $G(0)>I-p^{*} S^{a}$, optimal property rights are smaller than $p^{*}$.

The mathematical problem is the same as in (3.11), but now the corporation optimizes over $p$ given $v$. In the following lemma, optimal property rights are implicitly characterized as a function of decentralization $v$ :

Lemma 3.12. If $\frac{\partial \mathrm{RS} c}{\partial p}\left(v, p^{*}\right) \geq 0$, the optimal strength of property rights is $p^{*}$. If $\frac{\partial \mathrm{RS} c}{\partial p}\left(v, p^{*}\right)<0$, the optimal strength of property rights can be represented by a continuous and strictly increasing function $g_{p}:[0,1] \rightarrow\left[0, p^{*}\right]$ with $g_{p}(1)=p^{*}$.

Proof. When competition occurs, residual surplus increases monotonically as property rights weaken, thus the optimal level will be at most $p^{*}$. By definition, for weak property rights the functions $\Delta(v, p, I)$ and $\operatorname{RS}^{c}(v, p, I)$ are the same so we will refer only to residual surplus. If $\frac{\partial \mathrm{RS}^{c}}{\partial p}\left(v, p^{*}\right) \geq 0$, residual surplus falls if property rights weaken thus reaching a global maximum on $p^{*}$. If on the other hand $\frac{\partial \mathrm{RS}^{c}}{\partial p}\left(v, p^{*}\right)<0$, by concavity of residual surplus it follows that the optimal level must be strictly smaller than $p^{*}$ and strictly higher than $\widetilde{p}(v)$ (residual surplus is zero on $\widetilde{p}(v)$ by definition). Now fix $v$. Then the first order condition is given by

$$
\left.\frac{\partial \mathrm{RS}^{c}}{\partial p}\right|_{\left(v, g_{p}(v)\right)}=\frac{\partial e^{c}}{\partial p}\left[S^{\prime}\left(e^{c}\right)-1\right]+S^{a}\left(e^{a}\right)=0
$$

Totally differentiating we have

$$
\left[\left[S^{\prime}\left(e^{c}\right)-1\right] \frac{\partial^{2} e^{c}}{\partial p \partial v}+\frac{\partial e^{c}}{\partial p} \frac{\partial e^{c}}{\partial v} S^{\prime \prime}\right] d v+\left[\left[S^{\prime}\left(e^{c}\right)-1\right] \frac{\partial^{2} e^{c}}{\partial p^{2}}+\left(\frac{\partial e^{c}}{\partial p}\right)^{2} S^{\prime \prime}+S^{\prime} \frac{d e^{a}}{d p}\right] d g_{p}=0
$$

and using the signs calculated in Appendix A.1 we know that the first expression in parenthesis is strictly positive and the second one is strictly negative. It follows that $\frac{d g_{p}}{d v}>0$.

Thus (and as can be seen from Figure 6):

Result 3.4 (Endogenous strength of property rights). If $G(0)>I-p^{*} S^{a}$, a more decentralized corporation would choose stronger property rights, but never above $p^{*}$.

Last, since $\Delta$ is concave in $v$ and $p$, the optimal combination of property right strength and decentralization is found at the intersection of $g_{v}$ and $g_{p}$.

\subsection{Two extensions}

Small synergies Throughout the paper we have assumed that synergies are neither too large nor too small (i.e. $I>G(0)>I-p^{*} S^{a}$ ). Now we comment what happens if they are small. A 
formal characterization is in Appendix C.

As seen in Figure 7, the scope of corporate financing decreases. This is not surprising because the corporation's residual surplus falls and consequently, specialist financing is more attractive for a larger number of cases. Nevertheless, there still exists some corporate funding when property rights are weak which, as before, is efficient.

Competition with multiple organizations Throughout the analysis, we have assumed that there is only one organization of each type (specialist and corporation) that competes for talent. Here, we briefly comment on the analysis when the market comprises multiple organizations of each type. The main point is that the results established thus far would not be affected by such an extension.

To see why, notice, first, that increased competition does not affect the probability of talent leaving at date 1 since $p$ is exogenous. Thus, competition only affects who will finance talent exante. Now, recall that the boundary conditions (3.4) and (3.6) determine who will finance talent in each region of Figure 2. But, along these boundaries, organizations are left with no surplus anyway - talent grabs it all.

In contrast, organizations will in general grab surplus within each region: as seen, residual surplus there (3.2 and 3.3, respectively) is positive. The effect of increased competition from multiple organizations of the same type, then, is only to shift bargaining power to talent within each region and thereby dissipate this residual surplus. Thus, increased competition only affects surplus sharing within each region, but not who will finance.

\section{Applications}

This section uses the model to analyze several phenomena that characterize markets for talent. These markets differ in many important respects. At the same time, they share certain phenomena that we focus our attention on here. The first two applications (section 4.1) discuss two industriesTV shows and athletes' representation - that are dominated by large firms despite pervasive claims of self-dealing. Next, we suggest an explanation of why artists that work in creative activities such as advertising, movies or music exert a lot of effort, despite working for large companies (Section 4.2). Finally, we use the theory to suggest why corporations finance more than $90 \%$ of industrial $\mathrm{R} \& \mathrm{D}$, despite the fact that venture capitalists seem to offer better governance (section 4.3).

\subsection{Large versus focused firms: the organizational location of projects}

The model offers predictions on the location of projects that rely heavily on talent, and an explanation of how the costs typically associated with large firms can be moderated by the market 
for talent. We start by examining two settings that are natural arenas to apply the theory: the broadcast television industry, and the market of agents for talent.

\subsubsection{Television shows}

Broadcast television shows exemplify each of the building blocks of the model. Television shows like Seinfeld or Spin City are typically produced by production houses and their rights are acquired by television networks. ${ }^{17}$ Shows typically air for four years before going into syndication. Although advertising revenues accompany the airing of each first-run episode, costs are substantial during this period as well. In fact, profits are typically made during the syndication stage, where substantial revenues can be obtained selling prior episodes. Consequently, the initial four years can be thought of as the investment period (when $I$ is incurred) and syndication as the execution period. Last, since most shows revolve around a few characters, these projects are heavily dependent on talent that may walk away during the investment period $-p$ is small. Should one expect television networks to be independently owned or subsidiaries of entertainment conglomerates?

On the one hand, it is claimed that conglomerates exploit synergies. For example, shows aired on the primary network channel can be re-aired on secondary channels of the same firm, crosspromoted by these other channels, or repackaged for airing on foreign channels; similarly, experience in scheduling, promotional, and show selection strategies can be more easily transferred across channels inside a conglomerate. ${ }^{18}$ On the other hand, charges of self-dealing and expropriation by conglomerates can be a concern - recall the examples of the X-Files and NYPD Blue cited in the Introduction. As it turns out, entertainment conglomerates own five of the six national television networks. Result 3.1 suggests this is not surprising: the ability of talent to easily walk away (low p) diminishes the risk of expropriation, enabling conglomerates to exploit the benefits of synergies.

The behavior of market participants seems to confirm this logic. First, actors and producers engage in repeated relationships with media firms that have been repeatedly accused of self-dealing and interest conflicts. For example, after original contracts had elapsed, both Duchovny and Bochco negotiated new deals with Fox despite earlier lawsuits they had filed and eventually settled. Second, a direct implication of our model is that there will be less account manipulation as property rights weaken (Lemma 3.2). This suggests that in large firms who employ talent one will observe practices that tend to mitigate account manipulation. In fact, television networks often attempt to ensure that transactions with the rest of the conglomerate are conducted at arms-length. For example, at the time of the launch of the Fox broadcasting network in 1986, Fox executives announced their intention to "[...] establish an arm's-length relationship with its sister company, Twentieth Century

\footnotetext{
${ }^{17}$ Production houses may be independent or owned by a network.

${ }^{18}$ For an illustration of how large these intra-firm learning benefits can be, see Anand (2003), which also discusses additional benefits of common ownership.
} 
Fox Studios" and that "[...] we expect the network to survive and succeed without any benefit from the studios." 19

Each of these actions might appear puzzling at first. Typically, evidence on expropriation by firms might lead suppliers to refuse to deal with them in the future, and a loss of reputation. Similarly, the logic of attempting to mimic market transactions inside the firm has also been criticized by observers. For example, the Wall Street Journal sarcastically noted that "[...] aside from such pleasantries as delivering ABC paychecks in 101 Dalmations envelopes, Disney has so far failed to bring off a more basic synergy: melding the two corporations. [...] Initial moves to bring ABC into the Disney fold appear to have been more cosmetic than substantive." ${ }^{20}$ And, somewhat surprisingly, Disney's CEO Michael Eisner signaled "to the rest of Disney management to leave the network alone." ${ }^{21}$ The model suggests that neither of these behaviors should be surprising, and offers a common explanation for both. That is, the fact that star talent can easily walk away works to increase the cost to firms from self-dealing or expropriation. This is a straightforward application of the second-best principle: holdup problems can cancel out rather than add up. As a consequence, firms tend to structure internal transactions at close to arms-length. Even though this would imply that some synergies may be left unexploited, it preserves the willingness of talent to continue to work with large firms.

\subsubsection{Agents for talent}

Athletes, musicians, dancers, or speakers are often represented by agents. To fix ideas, consider the market for representation of athletes. While athletes are represented by individual agents and personal relationships are important, quite often agents are employees of firms. Consequently, holdup is of concern: agents can leave firms taking athletes with them, or athletes might themselves leave for another firm. Such departures are observed on occasion. More importantly, they are costly because relationships with athletes are nurtured for as long as ten years before they become stars. ${ }^{22}$

Holdup is likely to be a bigger problem for large firms for many reasons. First, relationships are embodied in agents who can walk away. Second, firms whose businesses span multiple areas and clients face an added disadvantage from potential interest conflicts. Last, setup costs into this business are negligible. Each of these characteristics - holdup by individual agents, low entry costs, and interest conflicts within large firms - might lead one to guess that this market should

\footnotetext{
${ }^{19}$ Ghemawat (1996).

20 "Relativity: Disney-ABC promised synergy in merger, so what happened?" Wall Street Journal, May 16, 1977.

${ }^{21}$ Ibid.

${ }^{22}$ For example, agents established relationships with the families of golf star Tiger Woods and tennis athletes Martina Hingis and Anna Kournikova since each was ten years old. Holdup concerns are also noted in other industries: one industry expert, commenting on the poaching of classical music singers by competing agencies, noted that "[...] it could take ten years for an agent to build a singer's career and another five before star fees come cashing in [...] You lose one artist and you're upset. You lose three stars and you're in trouble." (Anand and Attea [2002, p.8]).
} 
comprise thousands of individual agents. The evidence, however, is quite different. A few large firms represent most professional athletes. Striking as well is the dominant position of the top firm, International Management Group (IMG). In 2003, IMG represented over 30\% of top athletes in most sports and in some like golf and tennis - where holdup is likely to be more severe because of the absence of the "team effect" - IMG's market share was even higher, with its golf clients winning over $50 \%$ of all prize money in all PGA golf tournaments, and its tennis stars including six of the nine top-ranked women's players over the previous two decades and virtually all big-name tennis professionals.

Size alone cannot explain IMG's success. In contrast to other large firms in this market, IMG is neither well-capitalized (it is privately held) nor a subsidiary of a parent with deep pockets. Moreover, it has fewer than $5 \%$ of the employees of its largest competitor (Interpublic) and less than one-fourth of its revenues. Instead, IMG's distinguishing feature has been its deep vertical presence in the value chain of each sport. Consider golf, for example. Starting in 1962, when it first signed on golf star Arnold Palmer, IMG expanded into hosting and managing golf tournaments, designing and marketing golf courses, producing and distributing television programming for golf events, and operating training academies for golfers of different ages. By 2002, the firm had created more than 400 golf courses worldwide, hosted numerous golf tournaments on both the regular and senior men's tour, developed the Sony ranking system for professional golfers, broadcast live coverage for some of golf's most prestigious events, and ran the largest training academy for golf instruction.

One might conclude that IMG's expansion into different businesses was intended to diversify away its dependence on mobile talent. But, if anything, these expansions increased its dependence. For example, the most important determinant of the success of a golf event was the presence of top $\operatorname{stars}^{23}$; the profitability of course design operations was considerably higher if these courses were made host to golf events; and, investing in training academies in order to establish relationships at an early age with athletes who could eventually leave (in effect, increasing $I$ ) only exacerbated the holdup problem. Moreover, in contrast to its competitors who were broadly diversified beyond sports, IMG's expansions were largely limited to activities within the same sports in which they represented athletes.

As the model would predict, the advantage to IMG is not size or deep pockets, but synergies with talent - a high $G(v)$. For example, IMG created various non-standard, made-for-television golf events to showcase its golf $\operatorname{stars}^{24}$, leveraged their talent through instruction at training academies, and ensured that courses that its clients designed would host major events. Further, its entry

\footnotetext{
${ }^{23}$ Between 1998 and 2002, gate receipts at tournaments in which Tiger Woods participated doubled those at tournaments in which he did not.

${ }^{24}$ These include the Skins game featuring four players competing individually for large winnings in a friendly format, and the Battle of Bighorn featuring two-player teams in a similar format.
} 
into event hosting increased competition for talent by increasing purses offered at events. Some observers argued that, in addition to these benefits, hosting tournaments allowed IMG to schedule favorable starting times for its athletes and to control camera coverage ensuring longer exposure of its own clients. Moreover, since IMG clients captured approximately fifty percent of all prize money, and the firm received ten percent of these winnings, it could afford to offer larger purses for events - thereby giving it an advantage in competing for the right to host such events. ${ }^{25}$ The key point is that IMG's expansion into various businesses was not meant to diversify away from its reliance on mobile talent, but to reinforce it.

Furthermore, as in the model, the tradeoff between synergies and conflicts of interest is relevant here as well and possible quite severe. IMG's presence in different businesses and its representation of both individuals and teams, has led to frequent charges of interest conflicts and, on occasion, lawsuits. A recent example ocurred in late 2001, when IMG client and New York Yankees star Derek Jeter re-signed with the Yankees for 10 years and $\$ 189$ million, an amount substantially lower than what Jeter could have got from another team. Critics noted that Jeter's re-signing had considerably enhanced the value of IMG's just-signed $\$ 900$ million, 10-year television deal with the Yankees which contemplated the creation of a new television network to broadcast the Yankees. Typically, these concerns might be deleterious to IMG's ability to attract talent. But as in other activities studied here, (1) synergies with IMG benefit talent, and (2) at the same time, high outside options and the the fact that athletes can easily walk away limit expropriation. This is a reason why top athletes continue to migrate towards IMG, not away from it, despite the potential conflicts of interest. ${ }^{26}$

\subsection{Art versus commerce: high effort in large firms}

One often hears of the tension between "art" and "commerce". On the one hand, talented artistes, performers, and producers complain vigorously about working for bureaucratic large firms, whose culture is claimed to be damaging for creativity. For example, "movie directors complain about Hollywood, writers attack the corporate publishing conglomerates, [...] creators typically dislike the commercial compromises that they must make to achieve and maintain market access" (Cowen

\footnotetext{
${ }^{25}$ See Anand and Galetovic (2004) for details. Note that the model also explains why IMG would be most active in the discovery of talent via training academies: it was best positioned to exploit synergies (high $G(v))$.

${ }^{26}$ Similar issues appear in the organization of agents for classical musicians. As Caves (2000) notes, although personalized relationships yield individual agents an advantage, a single large firm, Columbia Artists Management Inc. (CAMI) has dominated the agents market since the 1920s. In this case synergies stemmed from the fact that CAMI represented conductors for the Philadelphia and New York Philharmonic orchestras, and conductors in turn were "key decision makers in recruiting orchestral soloists, so (their) dominance as an agent for conductors gave leverage in representing soloists." Moreover, unlike most agent markets where interest conflicts can compromise an agent's function, CAMI "managed repeatedly to be on both sides of transactions without protest from the contracting parties."
} 
[1998, p. 187-188]). Similar complaints are echoed by creative teams at advertising firms and by musicians about recording studios. And, as seen, complaints don't stop at blunt incentives or interference by managers: conflicts of interest and expropriation also occur. This tension highlights the fundamental tradeoff between incentives and synergies that confront large firms within the arts.

Ordinarily, one might expect these problems to severely blunt effort incentives. Yet, the evidence suggests the contrary. At an anecdotal level, one rarely hears of musicians deciding not to perform well, creative account teams content with pushing through mediocre ideas, or television actors "going through the motions." Some systematic recent evidence appears to confirm this view. For example, von Nordenflycht (2003) studies the relationship between public ownership and creativity (as measured by independent CLIO awards) in advertising over a long period. He finds that publicly traded advertising agencies were as competitive in the high-quality segment of the industry as in other segments, and received a disproportionately large share of creative awards for almost a decade following a change in ownership status from private to public (with some declines thereafter). Moreover, in a detailed analysis of the impact of commercial influences on the arts, Cowen (1998) argues that these influences have resulted neither in a decline in productivity nor in diversity of artistic output, and may even have had the opposite influence.

How can one reconcile this evidence of strong effort exertion with the criticism that large firms blunt incentives? Most explanations rely on some type of intrinsic motivation: that is, talented workers care about the quality of their output, not just pecuniary rewards. Caves (2000) summarizes this as the "art for art's sake" property of creative industries. Our model suggests a complementary explanation based on extrinsic motivation. The key observation is that markets for talent are characterized by strong outside options and weak property rights. The value of talent's outside option increases with effort and forces firms that rely on talent to reward it accordingly. As Result 3.1 states, outside options neutralize the impact of blunt incentives within firms. Yet, effort is high because of high outside options $\left([1-p] S^{c}[e]\right)$ that limits the scope for expropriation of talent by firms. ${ }^{27}$

Interestingly, this logic also explains why complaints about talent by firms are common. For example, managers often complain about having to dispense large advances to authors and

\footnotetext{
${ }^{27}$ Evidence on the ability of creative talent in the arts to generate valuable outside offers is ubiquitous. A recent example is book publishing. In January 2003 Random House fired one of its editors, Ann Godoff, after she failed to meet profitability targets. Within a month Godoff was hired to launch a new imprint at Penguin, Random's biggest competitor. Susan Peterson Kennedy, President of Penguin Group (USA), told the Financial Times "it is a rare opportunity for a distinguished editor and respected publisher such as Ann to become available." John Makinson, Chairman and CEO of Penguin Group Global, also alluded to the role of the different environments of the publishing houses: "[Godoff's] publishing skills are legendary and I am certain that, in the right environment, they will be rewarded with both creative and financial success." Moreover, the loss for Random turned out to be more severe than some had expected: more than thirty writers (including best-sellers John Berendt, Ron Chernow, and Ken Auletta) followed Godoff because of personal relationships, creating a notable hole on the prestigious Random list. (See Anand, Barnett and Carpenter [2004]).
} 
immense payouts to television stars and talk-show hosts. Lemma 3.5 says that the stronger are outside options, the larger is the share of surplus appropriated by talent. Were intrinsic motivation the only driver, by contrast, firms would, in effect, get a free lunch.

\subsection{Entrepreneurship versus intrapreneurship: why corporations finance most $R \& D$}

The spectacular success of some venture-capital backed firms over the last two decades has given rise to a view of venture capital finance as the normative benchmark for $R \& D$ governance. The reasons typically cited are the high-powered incentives offered to entrepreneurs by venture capitalists, the design of contract structures aimed at solving various potential conflicts between financier and entrepreneur (e.g., staged finance, syndication, carried interest for general partners, and various covenants and restrictions), the benefits afforded by the typical limited partnership structure that VCs employ, and the separate governance employed for each project that VCs invest in (e.g., separate boards and limited liability for each project; see Gompers and Lerner [1999a, 2001] for a thorough account of VC finance). Drawing on these analyses, casual observers often conclude that corporations should mimic VCs, and that adopting the governance structure employed by VCs may solve various inefficiencies in corporate finance.

The view that corporations are somehow "getting it wrong" seems to imply some shortcoming within these firms - supposedly stemming from inefficient governance structures, incentives to preserve the status quo that cause corporations to migrate away from optimal project selection, or simply the inability to select appropriate projects. Yet it is very difficult to reconclile these shortcomings with three facts. First, it is unlikely that corporate financing is merely an off-equilibrium phenomenon because VC activity still accounts for less than $10 \%$ of total R\&D finance (Gompers and Lerner [2001]). Moreover, between 1982 and 1996, the share of VCs in total R\&D finance increased a mere 1.09\% (Kortum and Lerner [2000]). Second, evidence in Gompers and Lerner (2001) indicates that despite the presence of VC finance in more than twenty sectors, more than $75 \%$ of $\mathrm{VC}$ finance occurs in four sectors, and more than $50 \%$ in computer hardware and software alone. And VC finance is non-existent in many sectors (e.g., media and entertainment) where the underlying project characteristics - possibility of mega-hits and reliance on talent - are similar. ${ }^{28}$ And third, in a careful and large-sample study of corporate venturing activities, Gompers and Lerner (1999b) find that when corporations do want to mimic VCs, they appear to do so rather well. ${ }^{29}$

\footnotetext{
${ }^{28}$ In describing the criteria used to evaluate what projects were worthy of venture finance, most venture capitalists point to the importance of talent. For example, Arthur Rock, one of the pioneering venture capitalists, was often quoted as saying that his criteria to select projects was based almost entirely on evaluating people, not projects.

${ }^{29}$ For example, based on an analysis of over 30,000 investments between 1983 and 1994 (Gompers and Lerner 1999b), the authors conclude that "corporate efforts appear to be as successful as those backed by independent venture organizations (using such criteria as the probability of a firm's going public)." (Gompers and Lerner, 2001).
} 
The model presented here offers some observations. First, and most obvious, it may be optimal for corporations not to mimic the structure of venture capital finance since, for example, committing to providing high-powered incentives typically sacrifices synergies. In other words, blunt incentives come with a countervailing benefit that is often ignored in the casual debate.

Second, there is a simple explanation why one does not see VCs engaged in the discovery of talent in every sector. The strength of property rights over project output, and the importance of synergies, varies across sectors, and VC finance is efficient and competitive only when property rights are strong. ${ }^{30}$

The last implication concerns empirical analyses of the relationship between source of finance and innovative output. Specifically, drawing causal links from success measures that employ patent outputs can be misleading: the model suggests that the well-established empirical correlation between specialist finance and patent output may arise from strong property right regimes being more conducive to VC finance, not the other way around. That is, VCs prefer innovations that can be patented whereas corporations are willing to finance projects even when patents are weak.

\section{Conclusion}

This paper studies competition in financing projects where talent is pivotal. Conventional wisdom says that talent requires strong incentives that are typically best provided by specialist financiers that grant substantial autonomy. In contrast, offering high-powered incentives within corporations typically sacrifices synergies, making corporations less suited to financing of such projects.

At the same time, endemic to markets for talent is the fact that ownership rights over embodied talent typically resides with talent, not with firms. The central message of this paper is that weak property rights of this sort can help investment incentives for corporations by relaxing the tradeoff between incentives and synergies. Then, because of their advantage in exploiting synergies, one should therefore expect corporations, rather than specialist financiers, to have an advantage in financing projects where talent is key. This logic is consistent with the fact that, despite the apparent advantage of specialist financiers in offering strong incentives, markets for talent are still heavily skewed towards financing by corporations.

A central feature of the model is the role of outside options on effort. In other words, effort incentives by talent are preserved via competition for talent through markets, rather than through contracts within organizations. Indeed, as shown, competition can offset blunt incentives offered through such contracts. Examining the effect of competition on principal-agent relationships in more detail may be a fruitful area of research.

\footnotetext{
${ }^{30}$ Indeed, although specialist private equity exist in media and entertainment, most argue that the presence of "strategic buyers" on virtually every deal puts them at a severe disadvantage.
} 
There are two efficiency results of interest that stem from the particular distortions studied here. The first distortion is specific to corporations: compared to specialist financiers, corporations find it more difficult to commit to making talent the residual claimant. In some cases this "surplus transfer" problem can offset the benefit of synergies, resulting in financing by specialists even though corporate financing generates larger surplus. This leads to the following efficiency result: corporate financing is efficient when observed, whereas specialist financing may not be. The result should not be surprising since the distortion of interest only impacts corporate financing.

The second distortion stems from weak property rights. Typically, models consider this distortion in isolation, leading to the commonly held belief that weak property rights can hurt investment incentives. The model here suggests that this relationship is not as straightforward: sometimes, weaker property rights can help rather than hurt. At first sight, this may somewhat strange. But this result is a straightforward application of the second-best principle: adding an extra distortion to a pre-existing one can cause them to cancel out rather than add up. Consequently, corporations may prefer weak property rights. Combined with the efficiency result above, this leads to the somewhat striking conclusion that weaker property rights can in some cases be socially optimal as well.

A growing body of empirical work has begun to challenge the notion that stronger property rights induce innovation. ${ }^{31}$ Similarly, analyses of the relationship between stronger non-compete contracts for employees and investment incentives typically confront the "California puzzle": despite the weakest enforcement of non-compete clauses in labor contracts by any state, it enjoys the most robust entrepreneurial activity. The model presented here offers one way to reconcile conventional wisdom on investment incentives with this recent evidence.

\section{References}

[1] Acemoglu, D. and S. Pischke (1998), "Why Do Firms Train? Theory and Evidence," Quarterly Journal of Economics, 113, pp. 79-119.

[2] Acemoglu, D. and S. Pischke (1999), "The Structure of Wages and Investment in General Training ," Journal of Political Economy, 107, pp. 539-572.

[3] Alchian A. and H. Demsetz (1972), "Production, Information Costs, and Economic Organization," American Economic Review 62, 777-795.

[4] Aghion, P. and J. Tirole (1994). "The Management of Innovation." Quarterly Journal of Economics 109, 11851209.

[5] Anand, B. (2003), "Making Sense of Media Conglomerates." Harvard Business School Working Paper.

\footnotetext{
${ }^{31}$ See, for example, Hall and Ziedonis' (2001) analysis of semiconductors, Sakakibara and Branstetter's (2001) analysis of the impact of the Japanese patent reforms in 1988, and Moser's (2003) analysis of 19th-century world fairs. Jaffe (2000) and Kortum and Lerner (2000) also question the causal link between increases in R\&D spending and patenting that started in the 1980s and stronger intellectual property rights that were implemented during the same period. These findings are consistent with large-sample surveys of managers by Levin et al (1987) and Cohen et al (2000) that reveal that patents are largely irrelevant as instruments of appropriability in a broad range of industries.
} 
[6] Anand, B. and K. Attea (2002), "International Management Group." Harvard Business School Case Number 9-702-409.

[7] Anand, B., K. Barnett and E. Carpenter (2004). "Random House." Harvard Business School Case Number N9-704-438.

[8] Anand, B. and A. Galetovic (2000), "Weak Property Rights and Holdup in R\&D," Journal of Economics and Management Strategy 9, 615-642.

[9] Anand, B. and A. Galetovic (2004), "Strategies That Work When Property Rights Don't," forthcoming in G. Libecap (ed.) Advances in the Study of Entrepreneurship, Innovation, and Economic Growth, volume 15.

[10] Anton, J. and D. Yao (1994). "Expropriation and Inventions: Appropriable Rents in the Absence of Property Rights." American Economic Review 84, 190-209.

[11] Anton, J. and D. Yao (1995). "Start-ups, Spin-offs, and Internal Projects." Journal of Law, Economics, and Organization 11, 362-78.

[12] Balmaceda, F. (2003), "Firm-sponsored General Training", forthcoming in Journal of Labor Economics.

[13] Bhagwati, J. (1971), "The Generalized Theory of Distortions and Welfare," in Bhagwati et al. (eds) Trade, Balance of Payments and Growth.

[14] Boldrin, M. and D. Levine (2003), The case against intellectual monopoly, manuscript in preparation, UCLA (available at http://levine.sscnet.ucla.edu/papers/ip.ch2.pdf)

[15] Boldrin, M. and D. Levine (2002), "The Case Against Intellectual Property," American Economic Review Papers and Procedings 92, 209-212

[16] Caves, R. (2000), Creative Industries: Contracts between Art and Commerce, Boston: Harvard University Press.

[17] Cohen, W., R. Nelson and J. Walsh (2000), "Protecting their Intellectual Assets: Appropriability Condition and Why U.S. Manufacturing Firms patent (or not)," NBER Working Paper No. 7552.

[18] Cowen, T. (1998), In Praise of Commercial Culture, Boston: Harvard University Press.

[19] Dessain, W., L. Garicano and R. Gertner (2003), "Organizing for Synergies", mimeo, Graduate School of Business, University of Chicago

[20] Gans, J. and S. Stern (2000), "Incumbency and R\&D Incentives: Licensing the Gale of Creative Destruction," Journal of Economics and Management Strategy 9, 485-511.

[21] Dessein, W., L. Garicano and R. Gertner (2003), "Organizing for Synergies," Graduate School of Business, Chicago, Working Paper.

[22] Ghemawat, P. (1996). "Fox Broadcasting Corporation." Harvard Business School Case Number No. 387-096.

[23] Gompers, P. and J. Lerner (1999a). The Venture Capital Cycle. Cambridge: MIT Press.

[24] Gompers, P., and J. Lerner (1999b). "Can Corporate Venture Capital Succeed? Organizational Structure, Complementaries, and Success." In Concentrated Ownership. National Bureau of Economic Research Conference Reports, edited by Randall Morck. Chicago: University of Chicago Press.

[25] Gompers, P. and J. Lerner (1999c). "An Analysis of Compensation in the U.S. Venture Capital Partnership." Journal of Financial Economics 51, no. 1: 3-44.

[26] Gompers, P. and J. Lerner (2001). The Money of Invention: How Venture Capital Creates New Wealth. Boston: Harvard Business School Publishing.

[27] Grossman, S. and O. Hart (1986), "The Costs and Benefits of Ownership: A Theory of Vertical and Lateral Integration," Journal of Political Economics 94, 691-719.

[28] Hall, B.H. and R. H. Ziedonis (2001), "The Patent Paradox Revisited: An Empirical Study of Patenting in the US Semiconductor Industry, 1979-95," Rand Journal of Economics, 32(1): 101-128.

[29] Hart, O. and B. Holmstrom (2002), "A Theory of Firm Scope," MIT Department of Economics, Working Paper.

[30] Hart, O. and J. Moore (1994), "A Theory of Debt Based on the Inalienability of Human Capital," Quarterly Journal of Economics 109, 841-879.

[31] Hellmann, T. (2002), "A Theory of Strategic Venture Investing," Journal of Financial Economics 64, $285-314$. 
[32] Holmstrom, B. (1989), "Agency Costs and Innovation," Journal of Economic Behavior and Organization 12, 305-327.

[33] Jaffe, A. (2000). "The U.S. Patent System in Transition: Policy Innovation and the Innovation Process," Research Policy, 29, 531-557.

[34] Levin, R., A. Klevorick, R. Nelson, S. Winter, (1987) "Appropriating the Returns from Industrial Research and Development," Brookings Papers on Economic Activity, Special Issue on Microeconomics, 783-820.

[35] Lipsey, R. G. and Kelvin Lancaster (1956). The General Theory of the Second Best," Review of Economic Studies, 24:11-32.

[36] Kortum, and J. Lerner (2000), "Assesing the Contribution of Venture Capital to Innovation," Rand Journal of Economics 31, 674-692.

[37] Mailath, G., V. Nocke and A. Postlewaite (2003), "Business Strategy, Human Capital, and Managerial Incentives," Working Paper.

[38] Morrison, A. and W. Wilhelm Jr. (2003), "Partnership Firms, Reputation, and Human Capital," mimeo, Oxford University.

[39] Moser, P. (2003). "How Do Patent Laws Influence Innovation? Evidence from Nineteenth-Century World Fairs." NBER Working Paper number W9909.

[40] Sakakibara, M. and L. Branstetter (2001), "Do Stronger Patents Induce More Innovation? Evidence from the 1988 Japanese Patent Law Reforms," Rand Journal of Economics, 32 (1), pp. 77-100.

[41] Sahlman, W. (1990), "The Structure and Governance of Venture Capital Organizations," Journal of Financial Economics 27, 473-521.

[42] Von Nordenflycht, A. (2003), "Selling Out: Public Ownership and Creativity in the Advertising Industry." MIT Department of Economics.

[43] Terviö, M. (2003), "Mediocrity in Talent Markets," University of California, Berkeley, Working Paper. 


\section{Appendix}

\section{A. A complete derivation of Figure 2}

In this appendix we fully characterize Figure 2. This amounts to derive and examine functions $\widetilde{p}, t$ and $h$.

\section{A.1. Weak property rights}

We begin by deriving function $\widetilde{p}:[0,1] \rightarrow\left(0, p^{*}\right]$. For each $(v, p)$ in $[0,1] \times\left[0, p^{*}\right]$, the corporation will be willing and able to finance if there exists some offer $F_{c} \geq 0$ such that

$$
\operatorname{RS}^{c}(v, p ; I) \geq 0
$$

and

$$
S^{c}-e^{c}-T\left(F_{c} ; v, p\right) \geq \pi^{a} .
$$

That is, the project is viable (condition [A.1]) and the corporation is able to transfer enough surplus to talent to prevent a holdup (condition [A.2]). Note that if condition (A.2) holds for some $F_{c}>0$, then it must hold for all smaller offers because the left side is linearly decreasing in $F_{c}$. In particular, the highest possible transfer to talent is made when $F_{c}=0$. The following lemma shows that condition (A.2) always holds when property rights are weak.

Lemma A.1. When $p<p^{*}$, there always exists some offer $F^{p}>0$ such that $S^{c}-e^{c}-T\left(F_{c} ; v, p\right) \geq \pi^{a}$ for all $F_{c} \in\left[0, F^{p}\right]$.

Proof. We know that $S^{c}-e^{c}-T\left(F_{c} ; v, p\right)$, i.e. talents payoff is maximized with effort level $e^{c}(v, p)$, which is independent of $F_{c}$. In particular, for $F_{c}=0$, talent's payoff is strictly higher than what he gets exerting effort $e^{a}(v, p)$

$$
\begin{aligned}
S^{c}-e^{c}-T(0 ; v, p) & =S^{c}-e^{c}-(1-v) p S^{c} \\
& >S^{a}-e^{a}-(1-v) p S^{a} \\
& \geq S^{a}-e^{a}-p S^{a} \\
& =\pi^{a},
\end{aligned}
$$

where the first inequality follows from $e^{c}$ being optimal and the second inequality from the fact that $v \leq 1$. The result follows by defining $F^{p}$ implicitly by $S^{c}-e^{c}-T\left(F^{p} ; v, p\right)=\pi^{a}$ and noting that $S^{c}-e^{c}-T(0 ; v, p)$ falls as $F_{c}$ increases.

Hence the corporation is always able to finance talent when property rights are weak. We now study condition (A.1). The following lemma shows that this function is concave.

Lemma A.2. $\operatorname{RS}^{c}(v, p ; I)=S^{c}-e^{c}+G(v)-\mathcal{C}(p ; I)$ is strictly concave in $v$ and $p$. Moreover, $\operatorname{RS}^{c}(v, 0 ; I)<0$ for all $v, \operatorname{RS}^{c}\left(v, p^{*} ; I\right) \geq 0$ with equality only for $v=0$.

Proof. Recall that

$$
\begin{gathered}
e^{c}(v, p) \equiv \arg \max \left\{S(e)-e-T\left(F_{c} ; v, p\right)\right\}, \\
e^{a}(p) \equiv \arg \max \{(1-p) S(e)-e\}, \\
e^{*} \equiv \arg \max \{S(e)-e\} .
\end{gathered}
$$

The surplus function $S(e)$ is increasing but marginally decreasing: $S^{\prime}>0, S^{\prime \prime}<0, S^{\prime \prime \prime}<0$ and $S(0)=0$. Synergies $G(v)$ fall with decentralization: $G^{\prime}<0, G^{\prime \prime}<0$ and $G(1)=0$. The three first order conditions for optimal effort are

$$
\begin{gathered}
S^{\prime}\left(e^{c}\right)=[1-(1-v) p]^{-1}, \\
S^{\prime}\left(e^{a}\right)=(1-p)^{-1}, \\
S^{\prime}\left(e^{*}\right)=1 .
\end{gathered}
$$


We calculate first, the signs of the derivatives of $e^{c}(v, p)$ for all $(v, p) \in(0,1)^{2}$. The borders are treated separately when needed. Defining $A \equiv 1-(1-v) p$ to simplify the expressions, we have

$$
\begin{gathered}
\frac{\partial e^{c}}{\partial v}=\frac{-p}{S^{\prime \prime}[1-(1-v) p]^{2}}=\frac{-p}{S^{\prime \prime} A^{2}}>0 \\
\frac{\partial e^{c}}{\partial p}=\frac{1-v}{S^{\prime \prime}[1-(1-v) p]^{2}}=\frac{1-v}{S^{\prime \prime} A^{2}}<0 \\
\frac{\partial^{2} e^{c}}{\partial v^{2}}=\frac{p}{\left(S^{\prime \prime}\right)^{2} A^{3} \underbrace{\left(A S^{\prime \prime \prime} \frac{\partial e^{c}}{\partial v}+2 p S^{\prime \prime}\right)}_{<0}<0} \\
\frac{\partial^{2} e^{c}}{\partial p^{2}}=-\frac{1-v}{\left(S^{\prime \prime}\right)^{2} A^{3}} \underbrace{\left[A S^{\prime \prime \prime} \frac{\partial e^{c}}{\partial p}-2(1-p) S^{\prime \prime}\right]}_{>0}<0 \\
\frac{\partial^{2} e^{c}}{\partial v \partial p}=-\frac{1}{S^{\prime \prime} A^{2}}+\frac{v}{\left(S^{\prime \prime}\right)^{2} A^{3}}\left[A S^{\prime \prime \prime} \frac{\partial e^{c}}{\partial p}-2(1-p) S^{\prime \prime}\right]>0
\end{gathered}
$$

Now we can find the signs of the derivatives of $\operatorname{RS}^{c}(v, p ; I)$

$$
\begin{gathered}
\frac{\partial \mathrm{RS}^{c}}{\partial p}=\frac{p(1-v)^{2}}{S^{\prime \prime}[1-p(1-v)]^{3}}+S^{a}, \\
\frac{\partial \mathrm{R} S^{c}}{\partial v}=\frac{p^{2}(1-v)}{-S^{\prime \prime}[1-p(1-v)]^{3}}+G^{\prime}(v), \\
\frac{\partial^{2} \mathrm{RS}^{c}}{\partial p^{2}}=\left[S^{\prime}\left(e^{c}\right)-1\right] \frac{\partial^{2} e^{c}}{\partial p^{2}}+\left(\frac{\partial e^{c}}{\partial p}\right)^{2} S^{\prime \prime}+S^{\prime}\left(e^{a}\right) \frac{d e^{a}}{d p}<0, \\
\frac{\partial^{2} \mathrm{RS}^{c}}{\partial v^{2}}=\left[S^{\prime}\left(e^{c}\right)-1\right] \frac{\partial^{2} e^{c}}{\partial v^{2}}+\left(\frac{\partial e^{c}}{\partial v}\right)^{2} S^{\prime \prime}+G^{\prime \prime}(v)<0, \\
\frac{\partial^{2} \mathrm{RS}^{c}}{\partial v \partial p}=\left[S^{\prime}\left(e^{c}\right)-1\right] \frac{\partial^{2} e^{c}}{\partial v \partial p}+S^{\prime \prime}\left(e^{c}\right) \frac{\partial e^{c}}{\partial v} \frac{\partial e^{c}}{\partial p}>0 .
\end{gathered}
$$

We conclude that the Hessian matrix is negative definite and the function $\mathrm{RS}^{c}$ is strictly concave.

Remark 1. Note that this conditions hold for all $(v, p)$ in $(0,1) \times(0,1)$.

Finally we compute the extreme values of $\mathrm{RS}^{c}$. In a fully centralized corporation, $v=0$ and talent will choose, $e^{c}(0, p)=e^{a}(p)$; with full decentralization she will choose first-best effort, $e^{c}(1, p)=e^{*}$; and similarly if $p=0$ $e^{c}(v, 0)=e^{a}(0)=e^{*}$. Then, $\operatorname{RS}^{c}$ is:

- Negative and decreasing in $v$ when $p=0$ :

$$
\begin{aligned}
\operatorname{RS}^{c}(v, 0 ; I) & =S^{*}-e^{*}+G(v)-\left[S^{*}-e^{*}-I\right] \\
& =G(v)-I \leq G(0)-I<0
\end{aligned}
$$

- When $p=p^{*}$, positive for $v=0$ and zero for $v=1$ :

$$
\begin{aligned}
\operatorname{RS}^{c}\left(0, p^{*} ; I\right)= & S^{a}-e^{a}+G(0)-\left[\left(1-p^{*}\right) S^{a}-e^{a}-I\right]=G(0)+p^{*} S^{a}-I>0 \\
& \operatorname{RS}^{c}\left(1, p^{*} ; I\right)=S^{*}-e^{*}+G(1)-\left(S^{*}-e^{*}\right)=0 .
\end{aligned}
$$

Thus, we deduce by concavity of $\operatorname{RS}^{c}$ in $v$, that $\operatorname{RS}^{c}\left(v, p^{*} ; I\right) \geq 0$ for all $v$ with equality only in $v=1$. Note also that the slope of $\operatorname{RS}^{c}$ respect to $v$ in $v=1$ is $\left.\frac{\partial \mathrm{RS}^{c}}{\partial v}\right|_{v=1}=G^{\prime}(1)<0$.

Remark 2. Concavity of residual surplus in $v$ and $p$ implies that the set of projects financed by the corporation, $\mathcal{C F}_{w}=\left\{(v, p) \in[0,1]^{2}: \operatorname{RS}^{c}(v, p ; I) \geq 0\right\}$, is a strictly convex set. Strictly convex closed sets in $I \mathrm{R}^{2} c a n$ be 
characterized by two separate functions, representing the "lower" and "upper" bounds of that set. Moreover, the function representing the lower bound must be strictly concave and the one representing the upper bound must be strictly convex (if not, then the set cannot be convex). In the characterizations of the bounds of corporate financing that follow (Propositions A.3, A.5 and A.6 below), we use this property of convex sets after determining whether we are on the lower or the upper bound, which is done by analyzing the sign of the partial derivative $\partial \mathrm{RS}^{c} / \partial p$ on that point. If positive, it means that we must be on a lower bound and vice versa.

The next proposition characterizes the border of the set $\mathcal{C} \mathcal{F}_{w}$ when property rights are weak.

Proposition A.3. Assume $I-p^{*} S^{a}<G(0)<I$. Then there exists a strictly convex function $\widetilde{p}:[0,1] \rightarrow\left(0, p^{*}\right]$ with $0<\widetilde{p}(0)<p^{*}$ and $\widetilde{p}(1)=p^{*}$ such that when $p<p^{*}, \operatorname{RS}^{c}(v, p ; I) \geq 0$ if and only if $\widetilde{p}(v) \leq p<p^{*}$.

Remark 3. Function $\widetilde{p}(v)$ is a subset of the lower bound of the set of $\mathcal{C} \mathcal{F}_{w}$.

Proof. As shown in Lemma A.2 residual surplus is strictly negative in $(v, 0)$ and strictly positive in $\left(v, p^{*}\right)$, except for $\left(1, p^{*}\right)$, when it is exactly 0 . By concavity and continuity in $p$, there exists a unique $\widetilde{p}(v)$ between 0 and $p^{*}$ such that $\operatorname{RS}^{c}[v, \widetilde{p}(v) ; I]=0$. By uniqueness of $\widetilde{p}(v)$, we must have $\widetilde{p}(1)=p^{*}$ because $\operatorname{RS}^{c}\left(1, p^{*} ; I\right)=0$, and $\widetilde{p}(0)$ must lie between 0 and $p^{*}$ because $\operatorname{RS}^{c}(0,0 ; I)<0$ and $\operatorname{RS}^{c}\left(0, p^{*} ; I\right)>0$. Continuity and strict convexity of $\widetilde{p}(v)$ follows by noting that $\partial \mathrm{RS}^{c} / \partial p$ is positive for $p=\widetilde{p}(v)$.

\section{A.2. Strong property rights}

When property rights are strong $\left(p \geq p^{*}\right)$ the specialist is always willing to finance. Hence the corporation will finance if

$$
\operatorname{RS}^{c}(v, p ; I) \geq \operatorname{RS}^{*}(p ; I)
$$

and

$$
\pi^{c}(0 ; v, p)=S^{c}-e^{c}-T(0 ; v, p) \geq S^{*}-e^{*}-I=\pi^{*}(I)
$$

jointly hold. As we saw in the text, condition (A.3) just says that the corporation finances only if more efficient. Condition (A.4) says that the corporation must be able to transfer enough surplus to talent.

We begin by finding the set of pairs $(v, p)$ such that (A.3) holds with equality. The following lemma is a preliminary necessary result:

Lemma A.4. $\Delta(v, p ; I) \equiv \operatorname{RS}^{c}(v, p ; I)-\operatorname{RS}^{*}(p ; I)=S^{c}-e^{c}+G(v)-S^{*}-e^{*}$ is strictly concave in $v$ and $p$ in $[0,1] \times\left[p^{*}, 1\right]$.

Proof. $>$ From the previous section we know that $\partial \Delta^{2} / \partial v^{2}=\partial^{2} \operatorname{RS}^{c} / \partial v^{2}<0$ and $\partial^{2} \Delta / \partial v \partial p=\partial^{2} \operatorname{RS}^{c} / \partial v \partial p>$ 0 . Hence, it remains to be shown that

$$
\frac{\partial^{2} \Delta}{\partial p^{2}}=\frac{\partial^{2}\left(S^{c}-e^{c}\right)}{\partial p^{2}}=S^{\prime \prime}\left(\frac{\partial e^{c}}{\partial p}\right)^{2}+\left(S^{\prime}-1\right) \frac{\partial^{2} e^{c}}{\partial p^{2}}<0,
$$

which follows from the concavity of $S$ and $\partial^{2} e^{c} / \partial p^{2}<0$.

Concavity of $\Delta(v, p ; I)$ implies that the set $\mathcal{C F}_{s}=\left\{(v, p) \in[0,1]^{2}: \operatorname{RS}^{c}(v, p ; I) \geq \operatorname{RS}^{*}(p ; I)\right\}=\{(v, p) \in$ $\left.[0,1]^{2}: \Delta(v, p ; I) \geq 0\right\}$ is convex. ${ }^{32}$ The next proposition characterizes the border of the set $\mathcal{C F}_{s}$.

Proposition A.5 (Characterization). There exists a concave and increasing function $h:[0,1] \rightarrow\left(p^{*}, 1\right]$, with $p^{*}<h(0) \leq 1$ and $h(v)=1$ for all $v \geq v_{h}$ such that $\Delta(v, p ; I) \geq 0$ if and only if $p^{*} \leq p \leq h(v)$.

Remark 4. Function $h(v)$ is a subset of the upper bound of the set of $\mathcal{C F}_{s}$.

\footnotetext{
${ }^{32}$ Note that the definition of the $\operatorname{set} \mathcal{C} \mathcal{F}_{s}$ is different from the one used above $\left(\mathcal{C} \mathcal{F}_{w}\right)$ because the conditions for corporate financing with strong property rights change. But the analysis is analogous because $\mathcal{C} \mathcal{F}_{s}$ is still a strictly convex set.
} 
Proof. Define $v_{h}$ implicitly by $\Delta\left(v_{h}, 1 ; I\right)=0$, which exists and is unique because $\Delta(v, p ; I)$ is concave and must change signs once: $\Delta(0,1 ; I)<0, \Delta(1,1 ; I)=0$ and $\left.\frac{\partial \Delta}{\partial v}\right|_{(1,1)}=G^{\prime}(1)<0$. For all $v \geq v_{h}$, both $\Delta(v, 1 ; I)$ and $\Delta\left(v, p^{*} ; I\right)$ are positive and thus $\Delta(v, p ; I)>0$ for all $p$ between $p^{*}$ and 1 (by concavity in $p$ ). We conclude that $h(v)=1$ for all $v \geq v_{h}$. In a similar way, for all $v<v_{h}$ we have that $\Delta(v, 1 ; I)<0$ and $\Delta\left(v, p^{*} ; I\right)>0$ and thus, it exists a unique $h(v)$ between $p^{*}$ and 1 such that, $\Delta[v, h(v) ; I]=0$. Clearly, $\Delta(v, p ; I)>0$ for all $p<h(v)$ and $\Delta(v, p ; I)<0$ for all $p>h(v)$. Continuity and strict concavity of $h(v)$ when $v<v_{h}$ follows by noting that $\partial \Delta / \partial p$ is negative for $p=h(v)$. Note that $h(v)$ is strictly concave in $\left[0, v_{h}\right]$ and constant if $v>v_{h}$.

Now we characterize the frontier of the set of pairs $(v, p)$ such that (A.4) holds.

Proposition A.6. There exists a continuous, strictly convex and increasing function $t:[0,1] \rightarrow\left[p^{*}, 1\right]$ with $t(0)=p^{*}$ and $t(v)=1$ for all $v \geq v_{t}$, such that $\pi^{c}(v, p) \geq \pi^{*}$ if and only if $p \leq t(v)$.

Proof. Define $\mathcal{C} \mathcal{T}_{s}$ as the set of combinations of $v$ and $p$ where the corporation is able to transfer as much as the specialist. Recalling that the highest possible transfer by the corporation is achieved by setting $F_{c}=0$, we can write $\mathcal{C} \mathcal{T}_{s}=\left\{(v, p) \in[0,1]^{2}: \pi^{c}(v, p) \geq \pi^{*}\right\}$, where we have omited the dependence of $\pi^{c}(v, p)$ on $F_{c}$ because is evaluated on $F_{c}=0$. Our aim is to characterize its frontier. First note that the specialist's maximum transfer $\pi^{*}$ is constant and the corporation's maximum transfer is strictly concave:

$$
\begin{aligned}
\frac{\partial \pi^{c}}{\partial p} & =-(1-v) S^{c}<0 \\
\frac{\partial \pi^{c}}{\partial v} & =p S^{c}>0 \\
\frac{\partial^{2} \pi^{c}}{\partial p^{2}} & =-(1-v) S^{\prime} \frac{\partial e^{c}}{\partial p}<0 \\
\frac{\partial^{2} \pi^{c}}{\partial v^{2}} & =p S^{\prime} \frac{\partial e^{c}}{\partial v}>0 \\
\frac{\partial^{2} \pi^{c}}{\partial v \partial p} & =S^{c}+p S^{\prime} \frac{\partial e^{c}}{\partial p}>0 .
\end{aligned}
$$

Applying the same argument used twice before we conclude that $\mathcal{C} \mathcal{T}_{s}$ is a strictly convex set and we'll be able to characterize its frontier as some strictly convex or concave function. Now we calculate the border values to see if $t(v)$ belongs to the upper (resp. lower) border of $\mathcal{C T}_{s}$, to establish the convexity (resp. concavity) of that function.

Since $e^{c}=e^{a}$ when $v=0$ it follows that $\pi^{c}(0, p)=(1-p) S^{a}-e^{a}$. Moreover we know that $p^{*}$ is defined to be the limit value of property rights such that the specialist is willing and able to finance, i.e. $S^{*}-e^{*}-I=\left(1-p^{*}\right) S^{a}-e^{a}$. Thus we have that $\pi^{c}\left(0, p^{*}\right)=\pi^{*}$ and necessarily $t(0)=p^{*}$. Since $\pi^{c}$ is increasing in $v, \pi^{c}\left(v, p^{*}\right)>\pi^{*}$ for all $v$, except when $v=1$ in which case the corporation is indistinguishable from the specialist. Now for $p=1$ and $v=0$, $e^{c}=0$ thus $\pi^{c}(0,1)=0<\left(S^{*}-e^{*}-I\right)=\pi^{*}$; for $p=1$ and $v=1, e^{c}=e^{*}$ thus $\pi^{c}(1,1)=S^{*}-e^{*}>S^{*}-e^{*}-I=\pi^{c}$. We conclude that there must exist some $v_{t} \in(0,1)$ such that $\pi^{c}\left(v_{t}, 1\right)=\pi^{*}$. For all $v<v_{t}$ the corporation will not be able to transfer enough surplus to talent. For all $v>v_{t}$, the corporation is able to transfer the necessary surplus for all relevant $p$ 's, so $t(v)=1$. Nevertheless, if $v<v_{t}$, and because $\frac{\partial \pi^{c}}{\partial v}>0$, there must exist a unique $t(v) \in\left[p^{*}, 1\right)$ such that $\pi^{c}(v, t(v))=0$. The convexity of $t(v)$ follows from the fact that those points lay on the upper border of the set $\mathcal{C} \mathcal{T}_{s}$ because $\frac{\partial \pi^{c}}{\partial p}<0$. Last, using the implicit function theorem in $\left[0, v_{t}\right)$,

which completes the proof.

$$
\frac{d t}{d v}=-\frac{\partial \pi^{c} / \partial v}{\partial \pi^{c} / \partial p}=\frac{t(v)}{1-v}>0
$$

\section{B. Proof of Lemma 3.4}

(Only (i) and (ii). (iii) is proven similarly.) Optimal effort in the three alternatives is determined as before. We must only show that talent cannot increase her payoff by changing her stay-or-leave decision. 
(i) Suppose $\max \left\{\pi^{a}, \pi^{*}, \pi^{c}\right\}=\pi^{a}$ and talent optimally chooses $e^{a}$. We have to show that she will leave independently of the contract being accepted. If she accepts the specialist's offer, then

$$
\begin{aligned}
(1-p) S^{a}-e^{a} & \geq S^{*}-e^{*}-F_{s} \\
& >S^{a}-e^{a}-F_{s},
\end{aligned}
$$

where the first inequality holds by hypothesis and the second because $e^{*}=\arg \max \left\{S(e)-e-F_{s}\right\}$. It follows that $(1-p) S^{a}>S^{a}-F_{s}$, i.e. the payoff from staying in stage 2 with the specialist is less than the payoff from leaving. Analogously, if she accepts the corporation's offer then

$$
\begin{aligned}
(1-p) S^{a}-e^{a} & \geq S^{c}-e^{c}-T\left(F_{s} ; v, p\right) \\
& >S^{a}-e^{a}-T\left(F_{s} ; v, p\right),
\end{aligned}
$$

where again, the first inequality holds by hypothesis and the second because $e^{c}=\arg \max \left\{S(e)-e-T\left(F_{s} ; v, p\right\}\right.$. It follows that $(1-p) S^{a}>S^{a}-T\left(F_{s} ; v, p\right)$, so the payoff from staying in stage 2 with the corporation is less than the payoff from leaving. Thus the decision is time consistent. $e^{c}$. Then

(ii) Similarly, we have to show that $S^{c}-F_{c} \geq(1-p) S^{c}$. Suppose $\max \left\{\pi^{a}, \pi^{*}, \pi^{c}\right\}=\pi^{c}$ and talent chooses

$$
\begin{aligned}
S^{c}-e^{c}-T\left(F_{c} ; v, p\right) & \geq(1-p) S^{a}-e^{a} \\
& >(1-p) S^{c}-e^{c}
\end{aligned}
$$

where the first inequality holds by hypothesis and the second because $e^{a}=\arg \max \{(1-p) S(e)-e\}$. Recalling that $T\left(v, p ; F_{c}\right)=v F_{c}+(1-v) p S^{c}$, it follows from the inequality that

$$
\begin{aligned}
S^{c}-v F_{c}-(1-v) p S^{c} & =v\left(S^{c}-F_{c}\right)+(1-v)(1-p) S^{c} \\
& >(1-p) S^{c} \\
& =v(1-p) S^{c}-(1-v)(1-p) S^{c} .
\end{aligned}
$$

It follows that $S^{c}-F_{c}>(1-p) S^{c}$ (talent's outside option) and her decision to stay is time-consistent.

\section{Small synergies}

Lemma C.1 (Small synergies). If $G(0)<I-p^{*} S^{a}$, there exists some $v_{0}>0$ such that $\widetilde{p}(v)=h(v)=p^{*}$ for all $v$ in $\left[0, v_{0}\right]$. The remaining convexity and monotonicity properties of $\widetilde{p}(v), h(v)$ and $t(v)$ still hold for $v \geq v_{0}$ but the particular shapes may change.

Proof. Function $t(v)$ doesn't change at all because it does not depend on synergies $G(v)$. But now residual surplus is negative in $\left(0, p^{*}\right)$ :

$$
\operatorname{RS}^{c}\left(0, p^{*} ; I\right)=G(0)+p^{*} S^{a}-I<0
$$

It is still zero in $\left(1, p^{*}\right)$ and decreasing in $v$ :

$$
\begin{gathered}
\operatorname{RS}^{c}\left(1, p^{*} ; I\right)=S^{v c}-e^{v c}+G(1)-\left(S^{v c}-e^{v c}\right)=0 \\
\left.\frac{\partial \mathrm{RS}^{c}}{\partial v}\right|_{\left(1, p^{*}\right)}=G^{\prime}(1)<0
\end{gathered}
$$

We conclude, by concavity of $\operatorname{RS}^{c}$ in $v$, that there exists some $v_{0}>0$ such that $\operatorname{RS}^{c}\left(v, p^{*}\right)<0$ for all $v<v_{0}$ and $\operatorname{RS}^{c}(v, p)>0$ for all $v>v_{0}$. Clearly, by the definitions of $\widetilde{p}(v)$ and $h(v)$, we have that $\widetilde{p}(v)=h(v)=p^{*}$ for all $v \leq v_{0}$. The rest of the characterization (when $v>v_{0}$ ), is analogous to Propositions (A.3) (for $\widetilde{p}[v]$ ) and (A.5) (for $h[v]$ ). 
Figure 1: Timeline

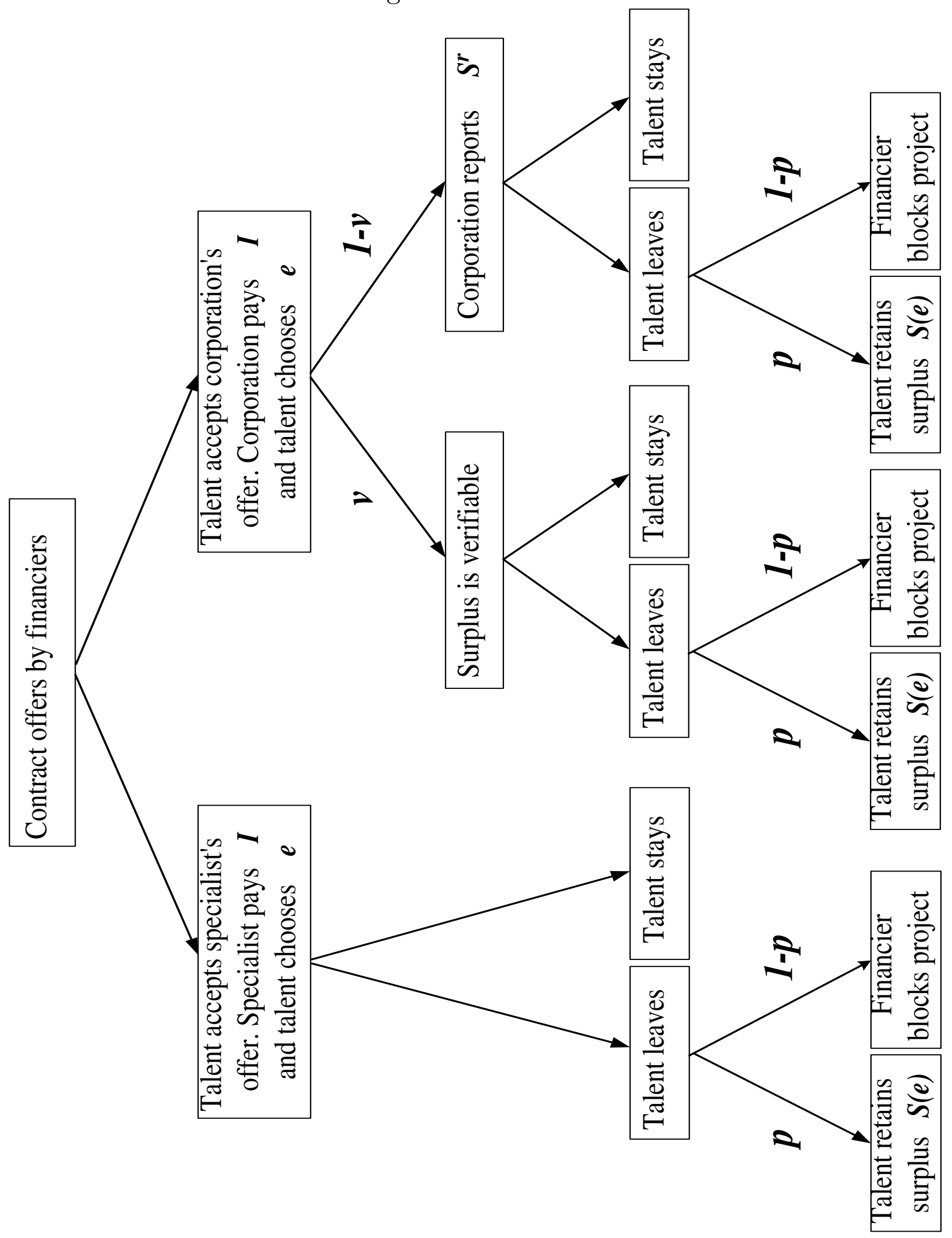


Figure 2: Talent financing

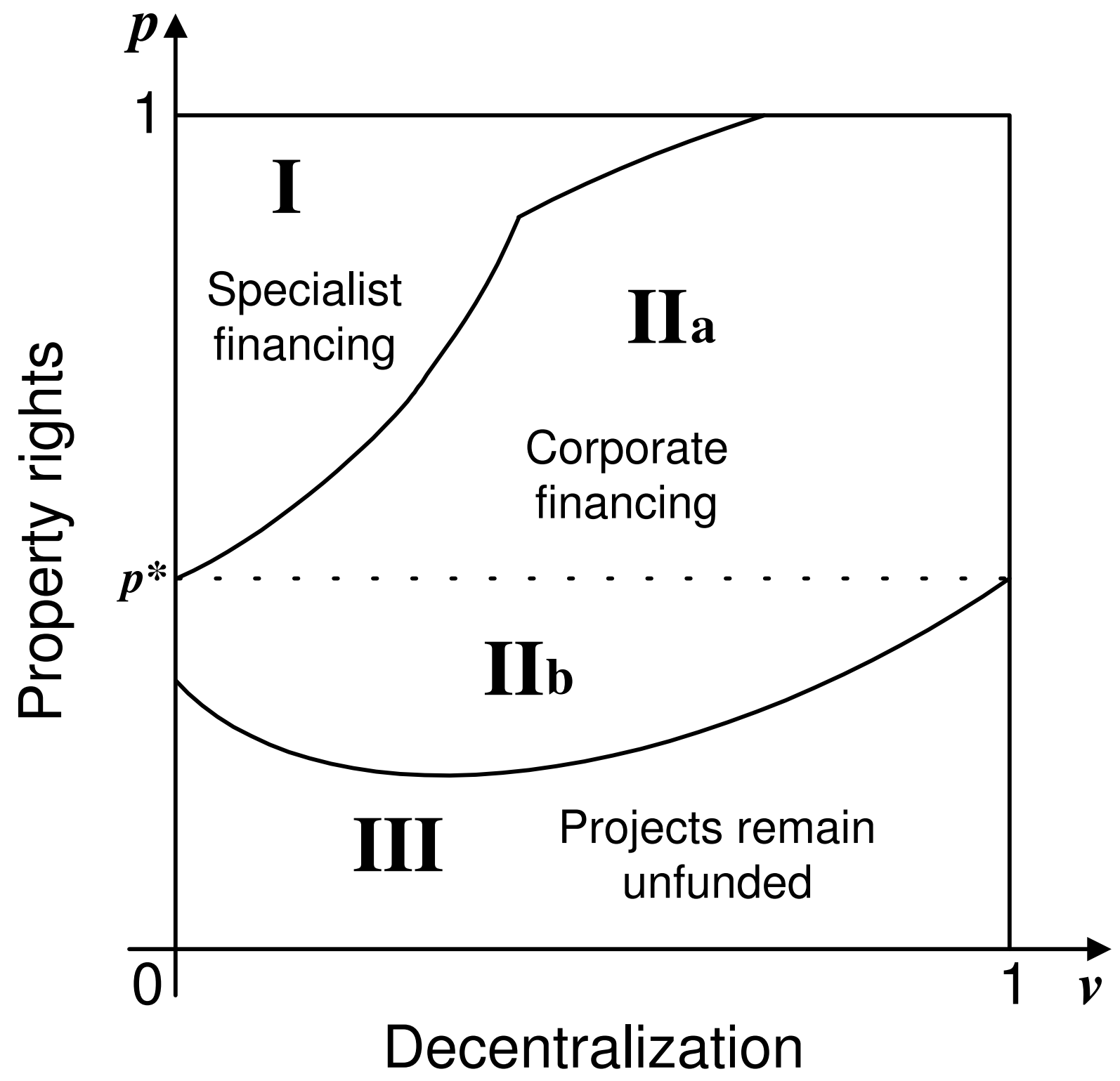


Figure 3: Residual surplus

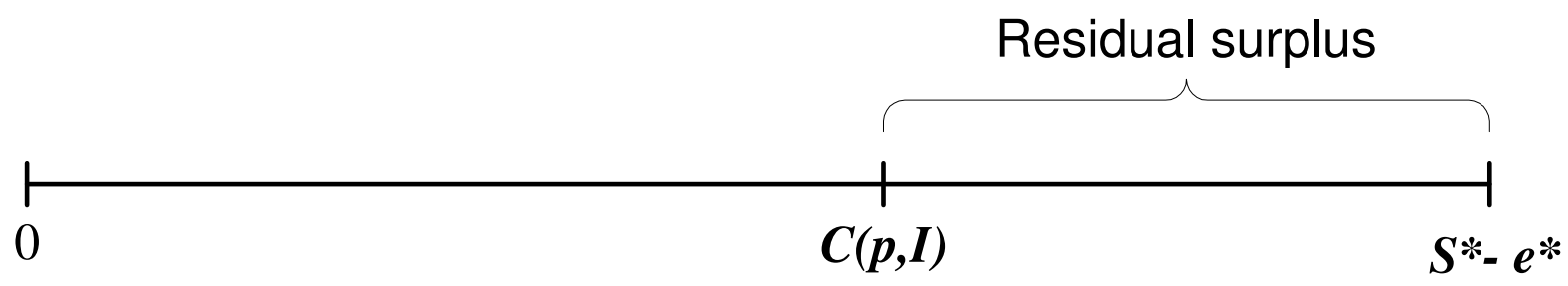

Residual surplus

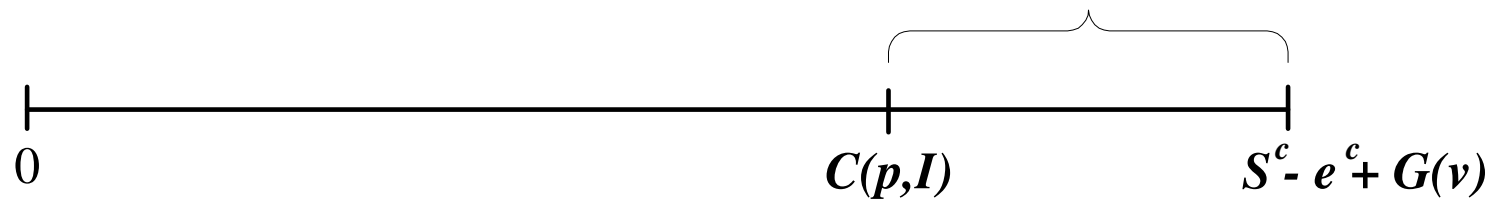

Figure 4: Corporation's residual surplus for a fixed $p$

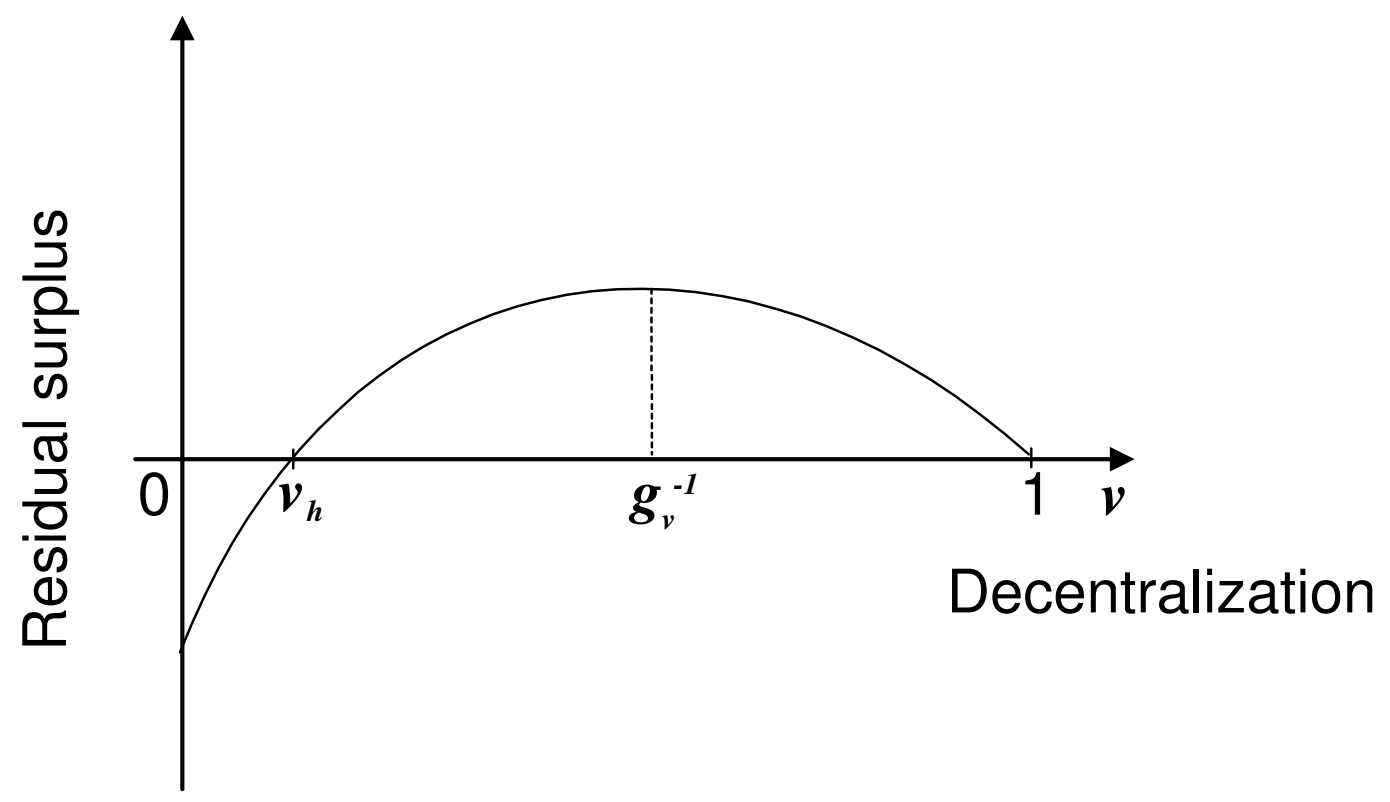


Figure 5: Efficiency with strong property rights

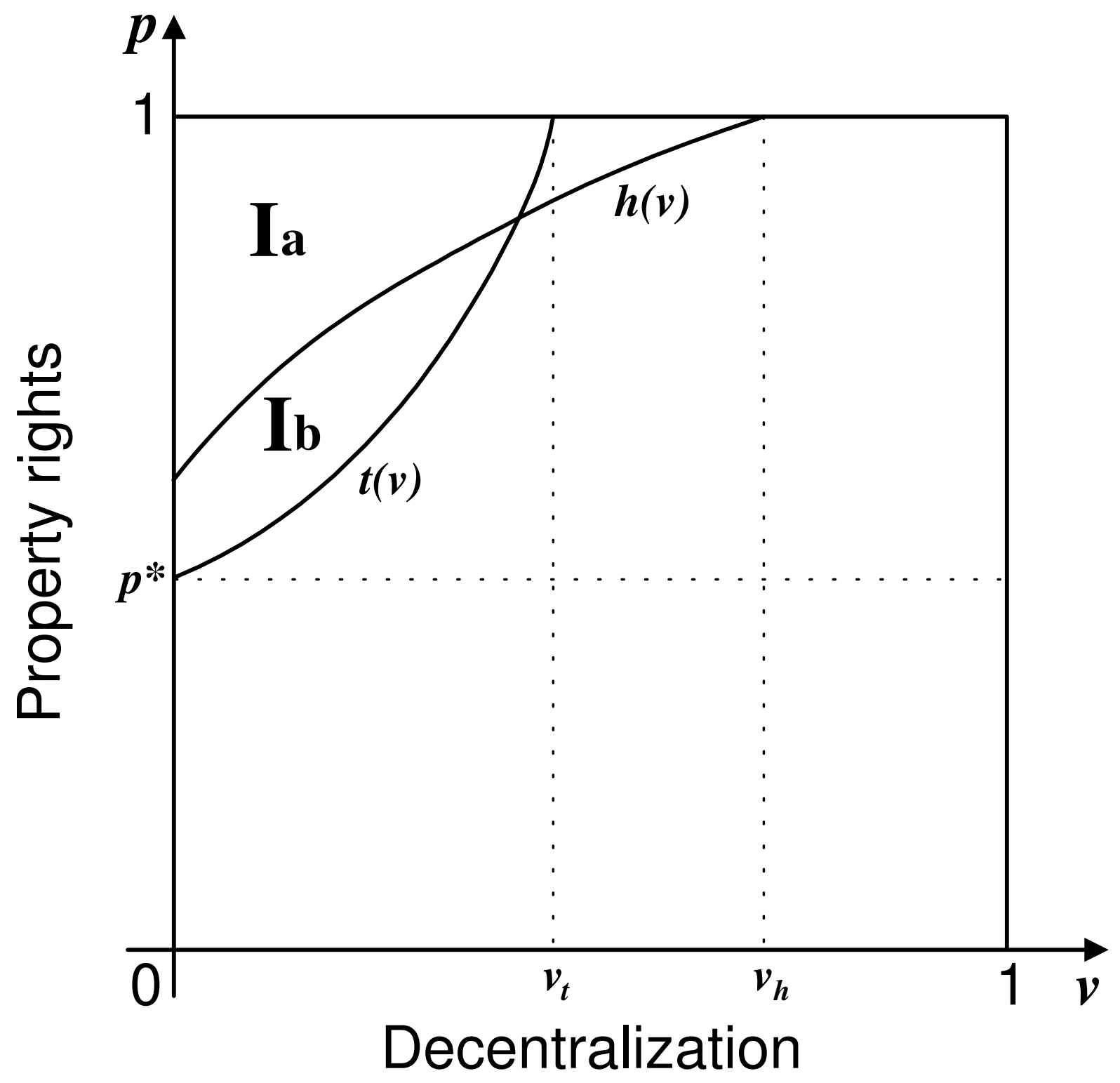


Figure 6: Optimal centralization and property rights

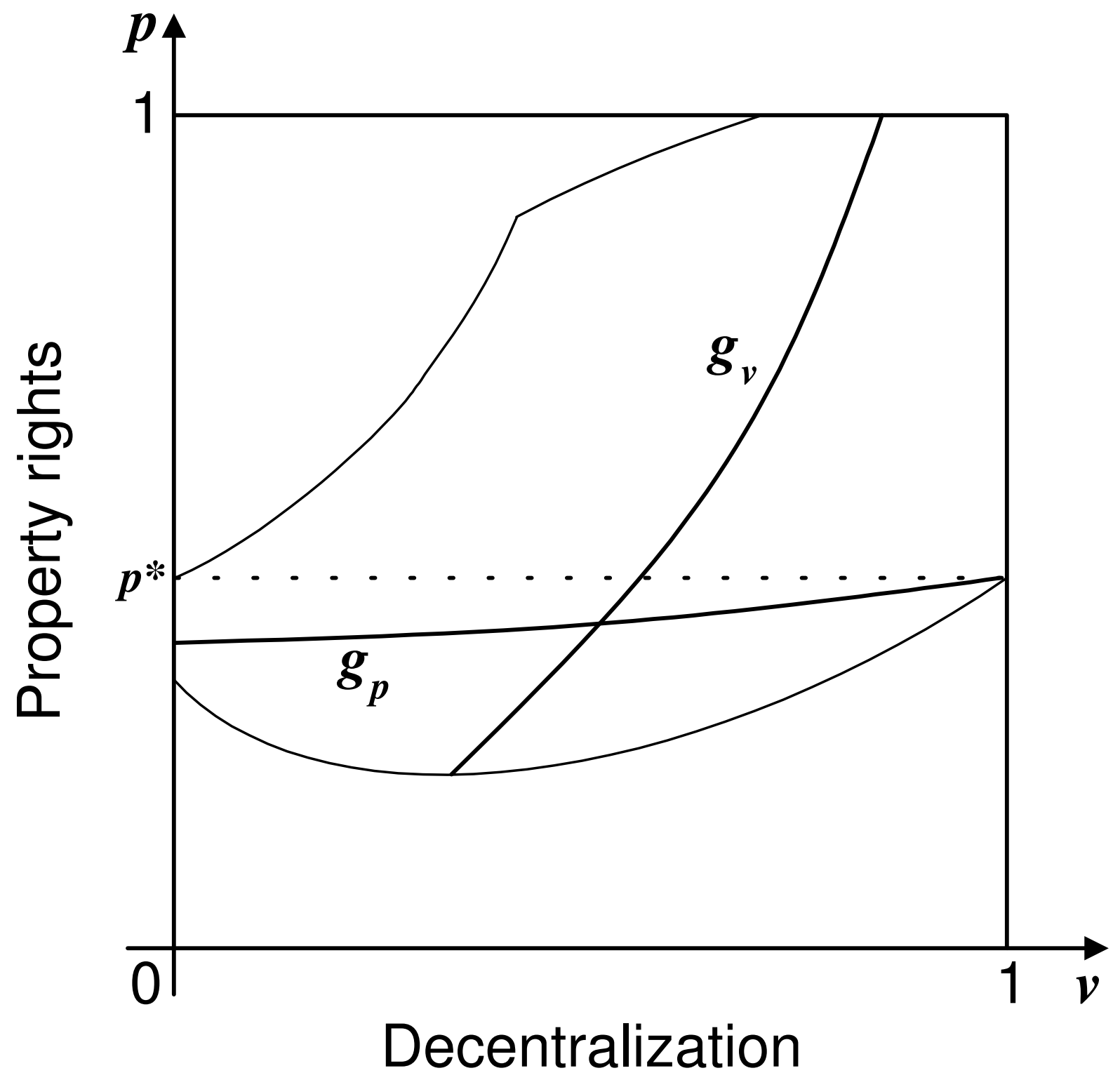


Figure 7: Financing when synergies are small

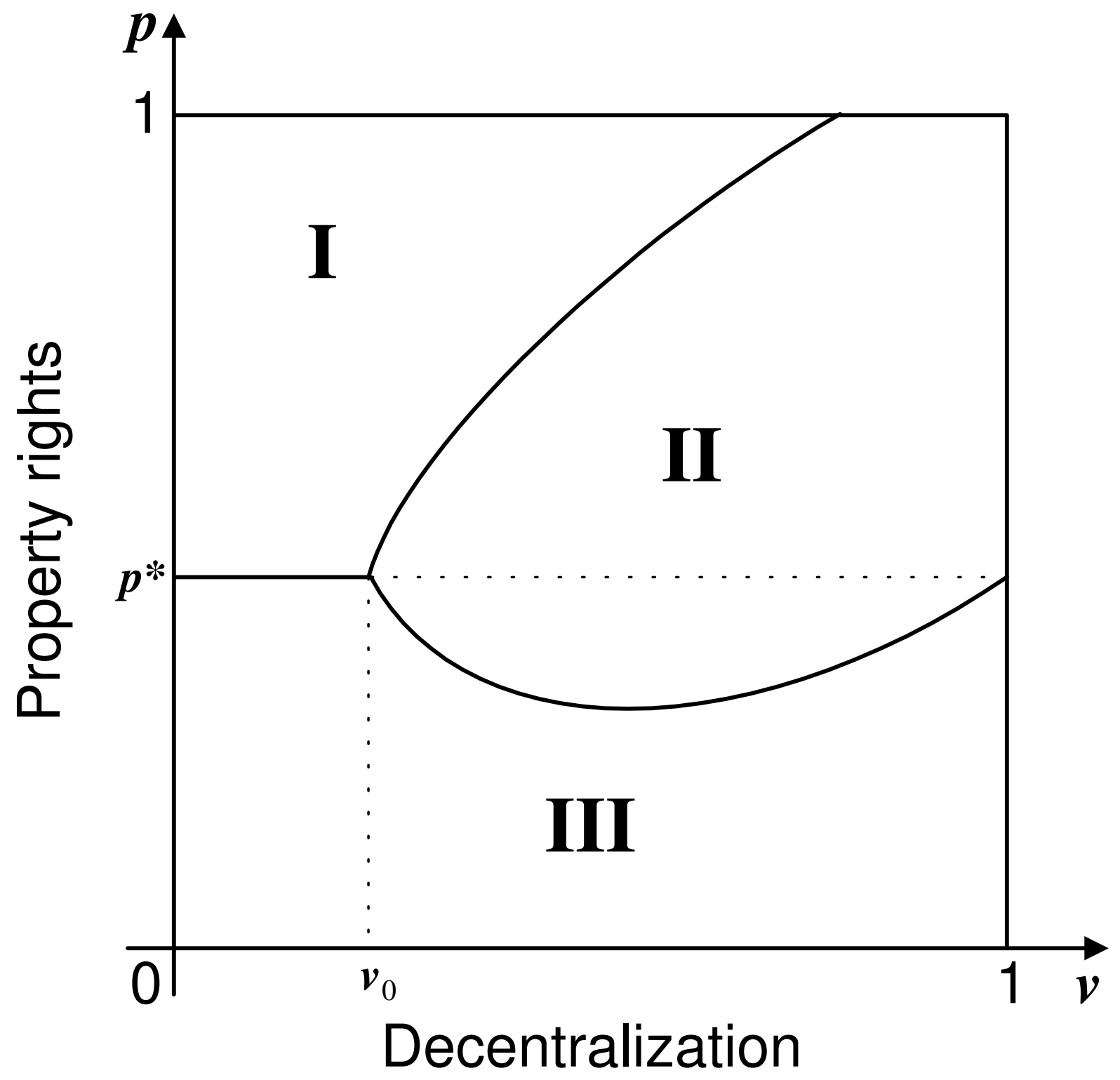

